UCRL--53506-Vol.2

DE84 013000

\title{
A Portable Microcomputer for the Analysis of Plutonium Gamma-Ray Spectra
}

\author{
Vol. II. Software Description \\ and Listings
}

W. D. Ruhier

ISPO Task A.104

Manuscript date: March 1984 


\section{CONTENTS}

Volurre I. Data Analysis Methodology and Hardware Description

Abstract

1. Introduction

2. Data Analysis Methodology

$\begin{array}{lll}\text { a. } 122-\text { to } 130-\mathrm{keV} \text { Region } & 10 \\ \text { b. } & 141-\text { to } 151-\mathrm{keV} \text { Rerion } & 12\end{array}$

c. 152- to 155-keV Region 12

d. 159- to 166-keV Region 13

e. 184- to 187-keV Region 14

f. 203- to 205-keV Region 14

g. 206- to 211-keV Region 14

h. 332- to 347-keV Region 15

i. $\quad 336-$ to $385-k e V$ Region 16

3. Operation Instructions 23

a. Operating Steps 23

b. Error Diagnostics 33

4. Hardware $\quad 35$

a. Central Processor Unit $\quad 35$

b. Programmable Read-Only Memory (PROM) 37

c. Random Access Memory (RAM) 40

d. LSI-11 Communication Modules 40

e. Input/Output Peripherals $\quad 49$

f. Power Supplies, Backplane, Fan, and Power Receptacle

5. Maintenance and Troubleshooting $\quad 54$

a. Preventative Maintenance $\quad 54$

b. Printhead Cleaning/Preventative Maintenance $\mathbf{5 5}$

c. Trouvleshooting 56

$\begin{array}{ll}\text { Acknowledgments } & 62\end{array}$

$\begin{array}{ll}\text { References } & 63\end{array}$

Volume II. Software Description and Listings

Abstract

1. Software Description

a. Main Program - IAEAPU 7

b. Data Analysis Subroutines $\quad 15$

c. Input/Output Subroutines 18

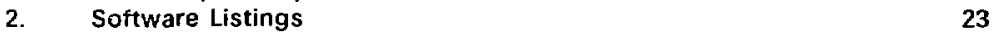




\section{FIGURES}

Volume I. Data Analysis Methodology and Hardware Description

1. The Portable Plutonium Isotopic Analysis Microcomputer Unit

2. A Detail Showing the Mathematical Components Used To Describe Gamma-Ray Peak Shape

3. Typical Data Analysis Printout of Results for the 120- to 220-keV Region

4. Voltage Selection Card Oriented To Indicate the Desired Supply Voltage

5. Removal of Paper Roll from Printer Mechanism

6. LSI-11/2 Module KD11-HA 36

7. Upper 8K MDB MLSI-MFV-004 PROM Module 38

8. Wirewrap Jumpers that Must Be in Place in PROM Module Locations 3B, 3F, and $4 \mathrm{~F}$

9. Wirewrap Jumpers that Must Be in Place in PROM Module Location 8F

10. DEC MSV-11D RAM Module $\mathbf{4 1}$

11. DEC DLV11-J Serial Interface 43

12. ADAC $1664 \mathrm{TL}$. Parallel Interface 45

13. Digital Pathways TCU-50 DYR Clock Module 48

14. Component Package Removed from Case 53

Volume II. Software Description and Listings

1. Flow Diagram of Main Program - IAEAPU 2

\section{TABLES}

Volume I. Data Analysis Methodology and Hardware Description

1. Energy Regions Analyzed by the Data Andysis Soitware

2. Pu and Am Half Lives Recommender in ANSI 15.22

3. Peripheral Device DLV11-J Register Address

Assignments

4. $1664 \pi \mathrm{T}$ Module Register Addresses and 8it Assignments

5. SILENA Input/Output Cable Wiring 


\section{ABSTRACT}

A portable microcomputer has been developed and programmed for the International Atomic Energy Agency (IAEA) to perform in-field analysis of plutonium gamma-ray spectra. The unit includes a 16-bit LSI-11/2 microprocessor, 32-K words of memory, a Z0-characcer display for user prompting, a numeric keyboard for user responses, and a 20-character thermal printer for hard-copy output of results. The unit weights $11 \mathrm{~kg}$ and has dimensions of $33.5 \times 30.5 \times 23.0 \mathrm{~cm}$. This compactness allows the unit to be stored under an airline seat. Only the positions of the $148-k e V{ }^{241} \mathrm{Pu}$ and $208-\mathrm{keV}{ }^{237} \mathrm{U}$ peaks are required for spectral analysis that gives plutonium isotopic ratios and weight percent abundances.

Vol. I of this report provides a detailed description of the data analysis methodology, operation instructions, hardware, and maintenance and troubleshooting. Vol. II describes the software and provides software listings. 


\section{SOFTWARE DESCRIPTION}

The following is a description of the software developed for the portable microcomputer to ana'yze plutonium gamma-ray spectra for plutonium isotopic abundances. Descriptions of the main program and the various subroutines are given. A flow diagram of the main program is shown in Fig. 1. Listings of the main program and subroutines are provided in Section 2.

The software was developed for a Digital Equipment Corporation (DEC) LSI-11/2 microprocessor with $16 \mathrm{~K}$ words of PROM and 12K words of RAM. The programs were compiled with DEC's FORTRAN IV V02.1-4 and linked with LINK V05.94A using a v03B-00 RT-11 operating system. (Note that if newer versions of DEC's RT-11 operating systems are used, the program may exceed available memory space because of increased memory requirements for the operating system.) The program was generated for a stand-alone environment in which the only input/output device supported by FORTRAN-level input/output is the terminal. To generate a stand-alone program, several special options must be specified at link time. The /LDA (absolute binary format) switch must be included in the LINK command string (see LINK command file listing in Section 2) to cause an LDA output file to be generated. The /INCLUDE switch must also be given to request the module \$SIMRT from the FORTRAN IV Library. The LDA file must be loaded into PROM by some type of PROM writing device. The final step before starting the program is to load into location $40_{8}$ of PROM the program transfer address that is given at the end of the LINK map listing (see Section 2). 


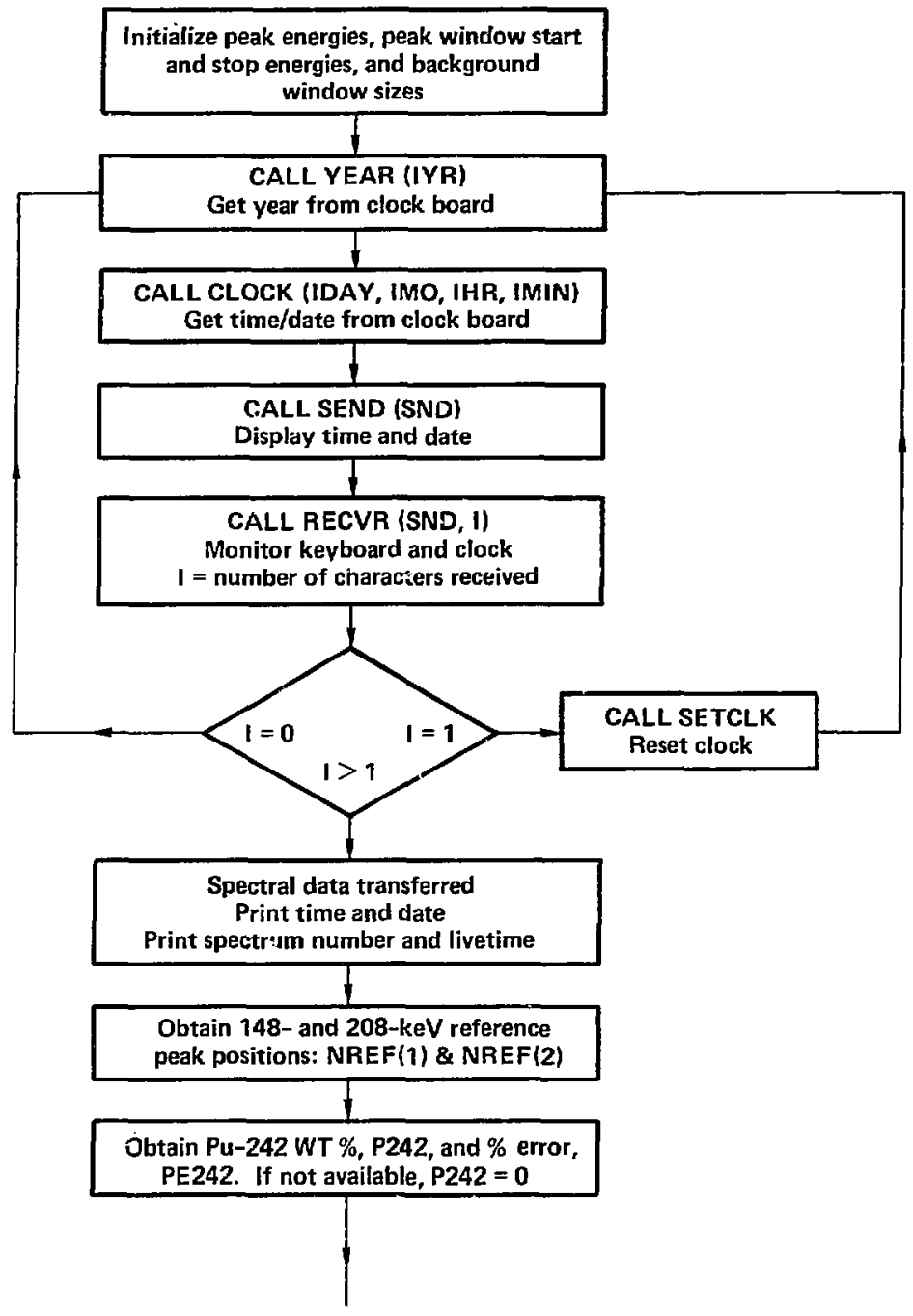

(Continued)

FIG. 1. Flow diagram of main program--IAEAPU. 


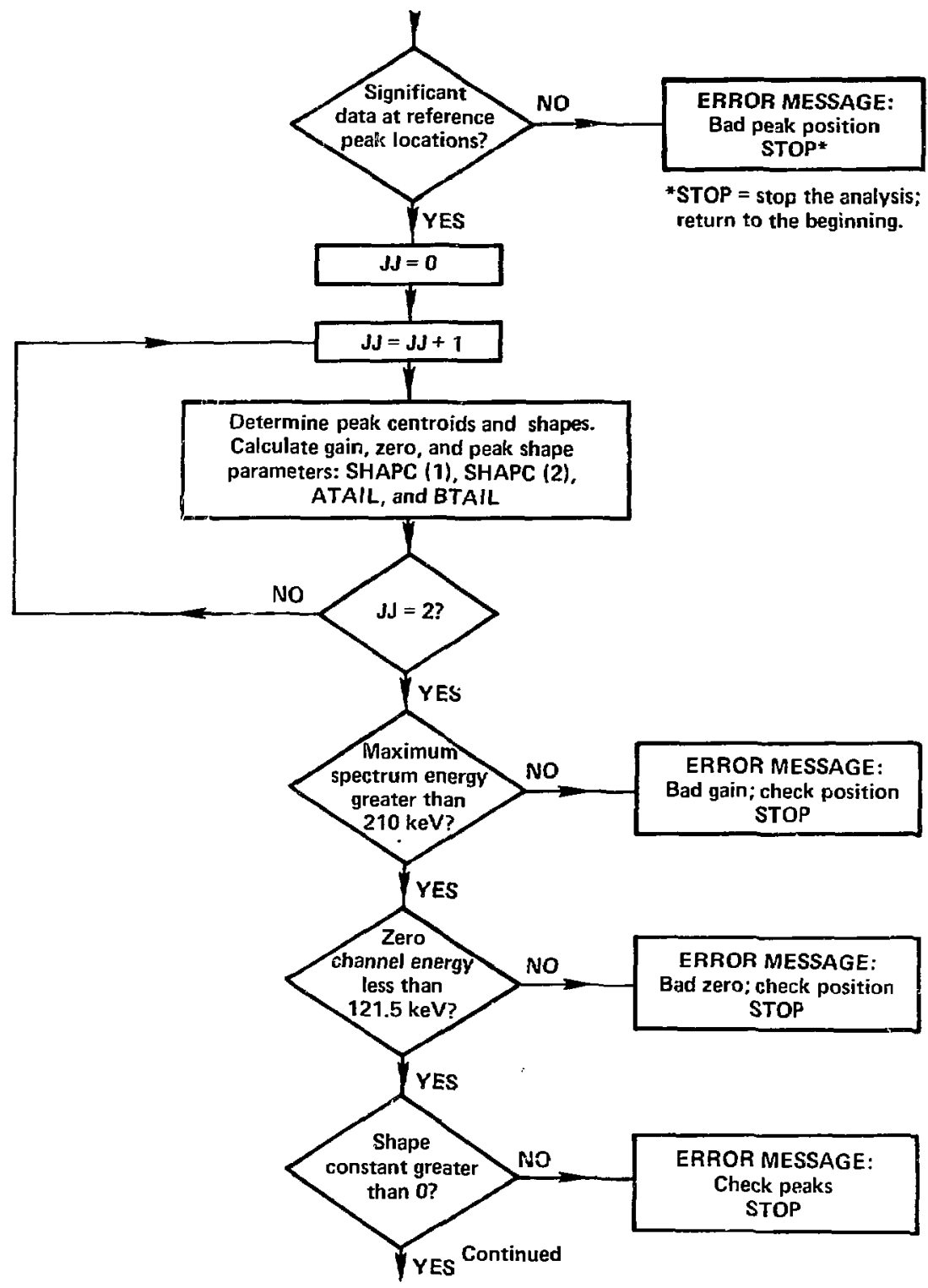

(Continued) 


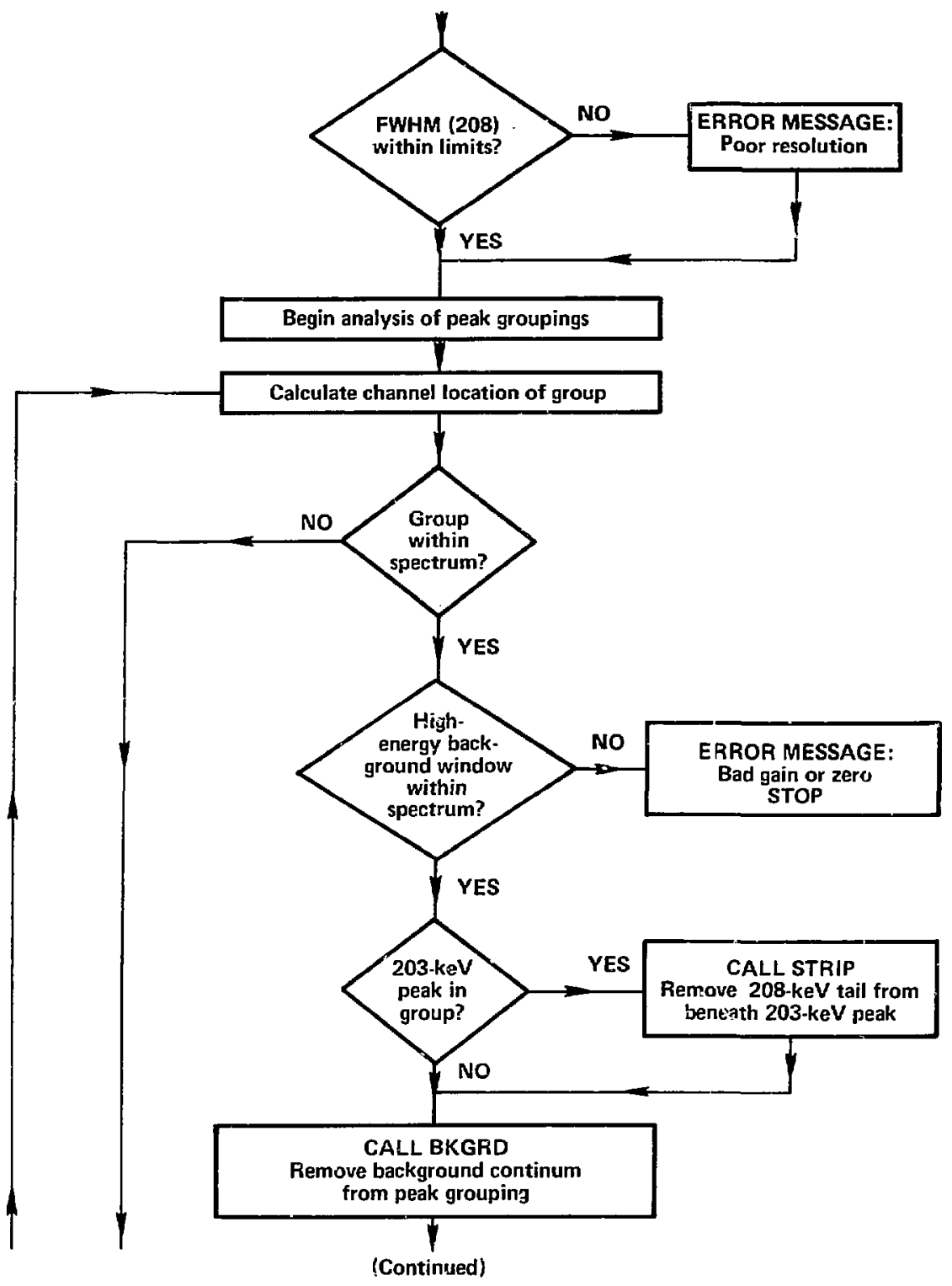




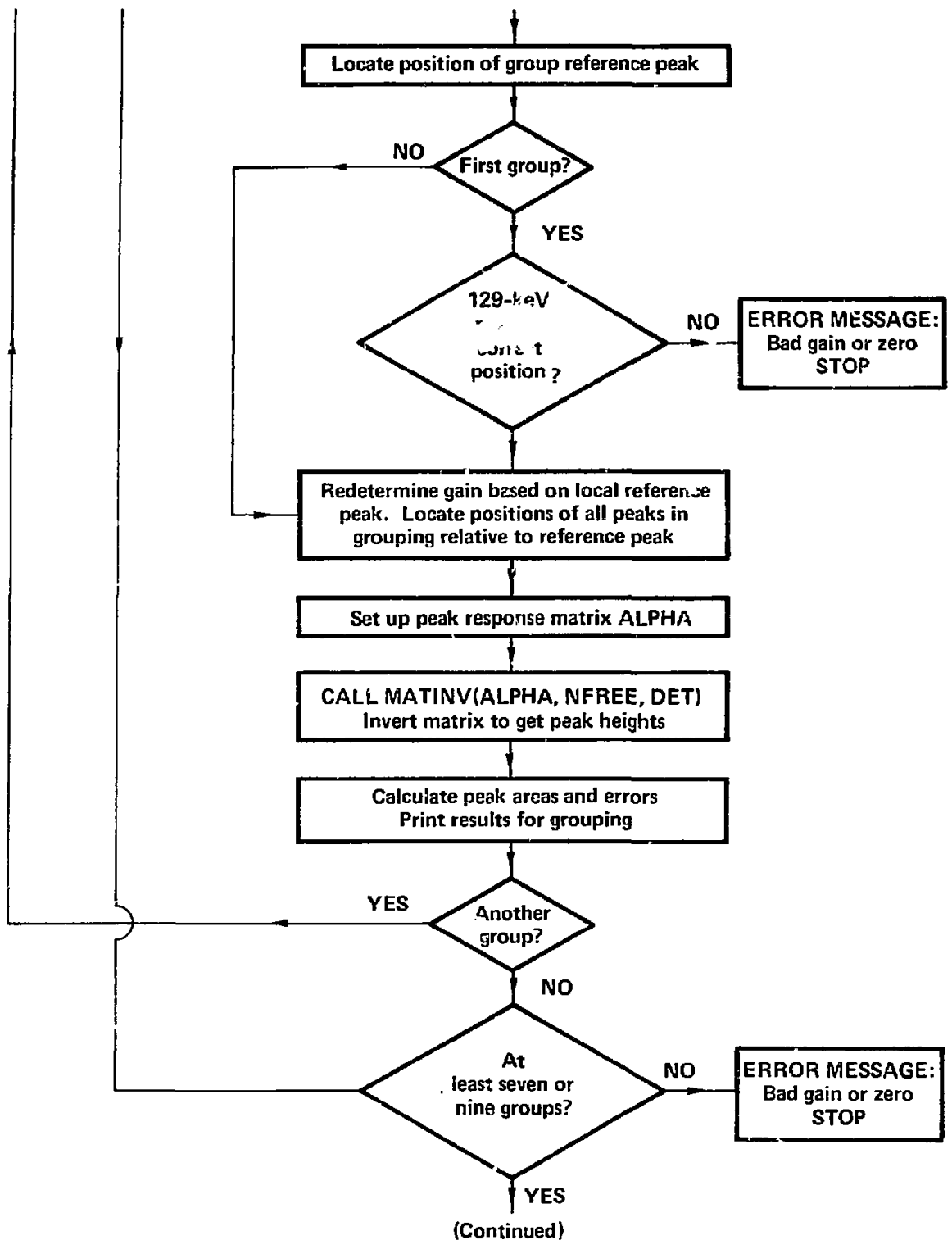




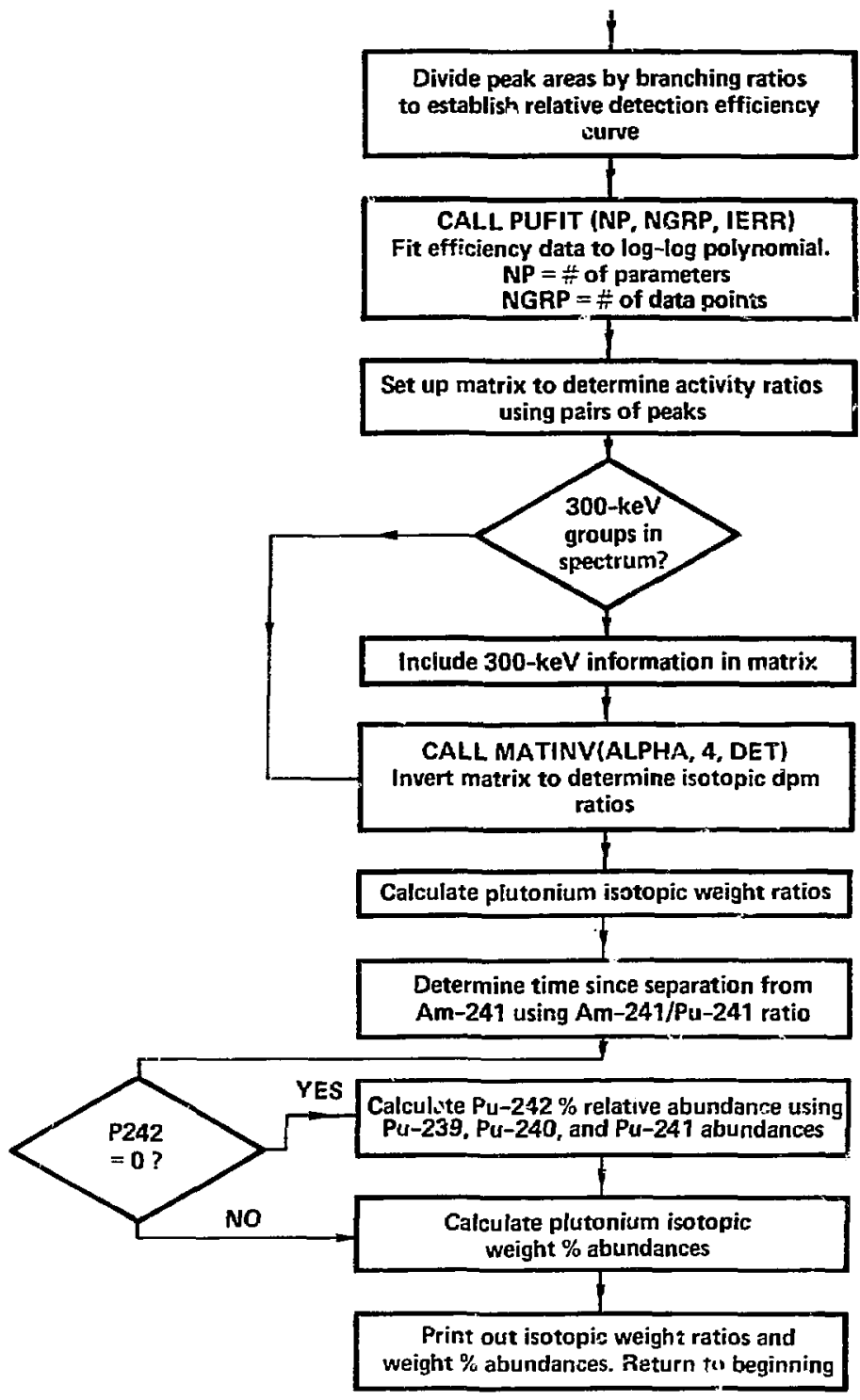




\section{a. Main Program - IAEAPU}

This program analyzes plutonium and ${ }^{241}$ Am gamma-ray peaks from 123 keV up te 383 keV for isotopic ratios and weight percent abunciances of total plutor um. It can anaiyze spectra contained in up to 2048 channels. For a complete analysis to oscur. ti:e spectrum must start at or below $121.5 \mathrm{keV}$ and include the $237_{\mathrm{U}}$ 208.0-xeV peik The only inputs required to the program are the positions of the $241 P_{U} 148.6-k e V$ anu the ${ }^{237} \mathrm{U} 208-\mathrm{keV}$ peaks. Input of the ${ }^{242} \mathrm{Pu}$ weight percent abundance is allowed, but not required. The remainirig information necessary for analyzing the plutonium spectra is contained ifl the program.

The program begins by reading the $t:-3 c /$ date from the clock board with the subroutines CLOCK arid YEAR. This information is loaded into the byte array. SND, and sent to the alphanumeric display with the subroutine SENin

Next, the program monitors the microprocessor keybourd for any input with the subroutine RECVR. The value o* I returned bV subroutine RECVR indicaters to the main program what action was requested. If $l=0$, th $\ldots$, the clock board ininute register has changed and the main program updates the time/date display. An $l=1$ indicates that the INIT function key a. the keyboard vis pressed; this is interpreted as a request for resetting the clock. The subroutine SETCLK is calied for this purpose. A value of $1>1$ indicates that the START key was pressed on the keyboard and the spt stral data have been transferred from the analyzer into the data array. ARRAY. Tine number of channels transferred is given by $\mathrm{I}$. The data transfer is pertormed by the subroutine SIREAD. which is called by the subroutine RECVR. 
Once a spectrum has been transferred from the analyzer to the microcomputer memory. the main program sends the current time/date and the spectrum number/livetime to tha printer by calling the subroutine SEND. It then prompts the user for the ${ }^{241} \mathrm{Fu} 148-\mathrm{keV}$ and the ${ }^{23} ; \mathrm{U} 208-\mathrm{keV}$ peak positions with the queries, 148 PEAK POS and 208 PEAK POS, respectively The responses are stored in the array NREF. The program next prompts the user for the ${ }^{242} \mathrm{Pu}$ weight percent abundance and the percent error on that value with the queries, WT \% PU-242 and PU-242\% ERR. The values ents ad are stored as P242 and PE242, respectively. If the user; enters a zero value for P242, there is no query tor the PEŹ42 value. The queries are displayed by calling the subroutine SEND. and the responses are read from the keyboard by the subroutine RECVR. No additional information is required from the user for analysis of the spectrum.

The first step in the data analysis is to determine the gein (GAIN), channel-zero energy (ZERO), and gamma-ray peak shape parameters: SHAPC(1), ATAIL, and BTAlL. In Section 2 of Vol. 1, (3HAPC(1) is the $K_{1}$ parameter in Eq. 3; ATAiL is the A parameter - tail amplitude - in Eq. 1; BTAlL is the B parameter - tail slope - in Eq. 1 times the gain.) 'Values for these parameters are obtained by analysis of the 148- and 208-keV reference peaks. Approximate values for several parameters are used initiallv in the analysis of the reference peaks; then the analysis is repeated using the results obtained in the first pass for these parameters.

Approximate gain and zero values are determined from the useg-provided reference peak locations. Sixty channels of data centered about the reference peaks are read into a working array, $Y$. The maximum count in the reference peak and minimum counts on each sije of the peak are obtained with the subroutines MAXVAL and MlivVAL. A statistical test is performed on this information to determine whether a peak exists at the location given by the user. The test requires that the difference between the 
maximum and minimum counzs exceed four times the square root of the maximum count. If this condition is not met, the program displays the message BAD PEAK POSITION and the program returns to the beginning. This condition may exist for three reasons: poor counting statistics in the reference peaks, incorrect value entered by the user for the reference peak position, or spectral data impsoperly transferred from the analyzer.

Before the reference peaks are analyzed for channel positions and shape parame*ers. the background distributions beneath the peaks are removed. The minimum counts found on either side of the peak are used as the corresponding background levels. The difference (step) between these levels, DBG, is proportioried at each channel beneath the peak by ratioing the partia! peak area up to that channel, YS, to the total peak area, YSUM. (See description of the background methodologv in Section 2 of Vol. I.)

The peak position, PKPS, and the peak width parameter, ALFA, are determined with the subroutine GFIT2. This subroutine fits a parabola to the natural logarithm of the net counts in the upper half of a peak. In addition to the backgro und corrected data in array Y, Inputs to this subrostine are the approximate position of the peak JPK within the array $Y$ and the parameters: ALFA, ATAlL, and BTAIL. ALFA is equal to $-4^{*} \operatorname{In}(2) /(F W H I M)^{\star *} 2$ where the FWHM is expressed in channels. GFIT2 returns the peak position PKPS, the peak height PKHT, and a redetermined value for ALFA. With this information, the subroutine CTAIL determines the peak tail parameters, ATAIL and BTAIL.

From the more accurate positions of the reference peaks, new gain and channel-zero energy values for the spectrum can be calculated. The tail parameter values are checked to ensure that they fall within some reasonable bounds. Poor counting statistics in thẹ reference peaks or unknown peak interferences could cause these 
values to fall outside the bounds. The bounds have been empirically cetermined and require that the value given by BTAIL/GAIN be greater than 1 and less than 3 . If these conditions are not met. BTAIL is set to 2."GAIN and ATAlL is set to BTAIL/10. If BTAIL falls within the given bounds, but ATAIL exceeds the value of BTAIL, then ATAlL is se: to BTAIL/10.

The peak width values determined for both reference peaks are used to determine the value of SHAPC(1) for the spectrum. SHAPC(1) is related to the "system" noise and is reevaluted for each measurement, and SHAPC(2) is related to the statistical nature of the charge collection process in the detector. SHAPC(2) is fixed to a constant value of 0.0017 in the program.

The analysis of the reference peaks is repeated with these new parameter values to ensure that the approximations used in the first pass do nct distort the final results. After the second pass, the values obtained in the analysis of the reference peaks for the gain, channel-zero energy, and th: FWHM of the 208-keV peak are printed out.

Several checks are made on these parameters to verify that an accurate analysis can be completed. The gain and channel-zero energy are checked to determine if the spectral regions required for the isotopic analysis are included in the spectrum. If the gain, charinel-zero energy, and maximum channel in the spectrum indicate that the maximum energy in the spectrum is less than $210 \mathrm{keV}$, the inessage BAD GAIN; CHECK PEAK POS is flashed on the display. The program cannot do a complete analysis if the 208-keV peak is not included, so the analysis is stopped and the program returns to the beginning. If the energy of channel zero is greater than or equal to $121.5 \mathrm{keV}$, the message BAD ZERO; CHECK PEAK POS is flashed on the display. Again the data analysis is stopped and the program returns to the beginning. If the peak shape analysis results 
in a value of SHAPC(1) less than zero, the message CHECK PEAKS is flashed on the display and the analysis does not continue. A negative SHAPC(1) occurs if either the 148- or the 208-keV reference peak does not have a Gaussian peak shape. This may result from very poor counting statistics, entry of an incorrect pesk position, or if either peak has a channel that overflowed. If the FWHM of the 208-keV peak exceeds $115 \mathrm{keV}$, the message POOR RESOLUTION is flashed on the display. This is to warn the user that the spectral resolution is not good and the results may be questionable. The analysis continues, however.

The next step in the program is to analyze seven or nine peak groupings in the SFectrum to determine gamma-ray peak areas. If the spectrum does not contain the 330 - or 370-keV regions, only seven groups are analyzed. Each group may contain anly one peak or a multiplet of overlapping peaks. The beginning and ending energies of the groups are stored in the arrays ENSTCH and ENECH. The number of channels used to determine the levels on both sides of each group are stored in the arrays NBG 1 and NBG2.

The channel location of the region to be analyzed is detsmined from the gain and channel-zero energy valises. Cnce the starting channel of the group IST and the number of channels NDPTS in the group have been determined, a check is made to ensure that the entire group is contained in the spectrum. A separate check is made to determine if the upper background window overlaps the end of the spectrum. If it does overlap, the program reduces the size of the upper background window, if possibie, to allow it to fit within the spectrum. If its size must be reduced to zero width, the analysis is stopped and the message BAD GAIN CP ZERO is displayed. Before locating the 330- and $370-\mathrm{kev}$ groups, the gain must be reevaluated by determining the position of the ${ }^{239} \mathrm{Pu}$ 375-keV peak. This is done in case of nonlinearity in the spectrum. 
The next step is to determine the average hackground levels on both sides of the group with the subroutine AVE. The background distribution beneath the peak(s) is calculated and subtracted channel by channel from the group with the subroutine EKGRD. If the 203.5-keV peak is being analyzed, an additional step is taken to remove any counts from the region caused by the 208-keV peak tail. This is done with the subroutine STRIP.

After removing the background, the reference peak in each grouping is located with the subroutine GFIT2. For the first peak grouping, the 120-keV region. the positicn of the 129.3-keV peak is checked to ensure that the correct ieference peaks were used. If the position of the 129.3-keV peak is found to be incorrect based on the gain and zero-channel energy, the message BAD PEAK POSITION is displayed and the analysis is stopped.

The next step in the analysis of a peak grouping is to load the arrays PKHT and NXFLG with the information needed for fitting the peak grouping to determine individual peak areas. The byte array STR contains the information for how these arrays are to be loaded. This array can be divided into nine parts. Each part applies to one of the nine peak groupings. The first value in each part gives the number of peaks in the grouping. For instance, the first six in the array (see program listing) indicates thas there are six peaks in the first grouping. The remaining byte values for each part indicate whether the height (area) of each peak is a frfe parameter or if it is fixed relative to another peak. These byte values are loaded into the NXFLG array, if a value is zero or is equal to the number of peaks in the group, the corresponding peak height is a free parameter. Any other value indicates that the corresronding peak height is ratioed relative to the free peak height indicated by that value. For instance, in the first grouping the value 3 for the second, third, and fourth peaks indicates that the heights of 
these peaks are ratioed to the height of the third free peak, which in this case is the last peak. The corresponding ratios are obtained from the RATIO array and loaded into the appropriate locations in the PKHT array. The peak that has a value equal to the number of peaks in the grouping is the peak to which the relative positions of all the other peaks are fixed.

Now a set of linear equations is formed and fit simultaneously to the net data channels in the group with the peak heights as the unknowns. The calculational method is to Form the matrix (peak response matrix) of linear equations ALPHA and to solve it by the method of weighted least-squares. The weights WT are the variance of the approximate gross channel counts. The peak heights PT are obtained by inverting the raatrix ALPHA with the subroutine MATINV and multiplying the inverted matrix by the matrix SUM. The diagonal matrix elements of the inverted matrix of weighted normal equations are used for assigning errors to the results. The peak areas are determined from the peak heights by raking the integrals of the corresponding Gaussians. The errors on the areas are determined by taking the square root of the sum of the square of each neak height error and the square of the statistical uncertainty in the background. The resulting peak energies, areas, and errors are then printed out. For those peaks whos: heights are fixed relative to another peak, the error value is replaced by the term FIXD in the printout.

When the program determines that there are no more peak groupings to be analyzed, it checks to make sure that at least the first seven groups were analyzed. If fewer than seven groups were found and analyzed, it displays the message BAD GAIN OR ZERO and the analysis is stopped. 
The peak areas must be corrected for detection efficiency before isotopic ratios can be determined. These corrections require determination of the overall detection efficiency for the gamma rays emitted by the sample. A self-calibration technique is used to obtain the necessary relative detection efficiency corrections from peak areas in each spectrum measured. Areas of the $129.3-$ and $203.5-k e V$ peaks of ${ }^{239} \mathrm{Pu}$ and the 164.6 and 208 . $-\mathrm{keV}$ peaks of ${ }^{241} \mathrm{Pu}$ are corrected for gamma-ray branching intensities, and the natura! logarithm of these values is fitted to a quadratic function of the natural logarithm of the energy (MeV). An additional coefficient is required in the fit to noimalize the ${ }^{241} \mathrm{Pu}$ data points to the ${ }^{239} \mathrm{Pu}$ data points. A weighted least-squares technique is used and is done with the subroutine PUFIT. If the 330- and 370-keV peak groupings are included in the spectrum, the $345.0-$ and $375.0-k e V{ }^{239} P_{u}$ peaks are also used in the determination of the relative detection efficiency. In this case, a cubic function is used to fit the data. The results of this analysis allow calculation of tire detection efficiency at any energy and therefore the correction of any peak area.

To determine plutonium isotopic ratios, appropriate peak areas from various energy regions are incorporated into a set of linear equations that are solved by the method of least squares (see Eq. 6 in Section 2 of Vol. I). Peak area ratios are the dependent variable, white the isotopic activity ratios are the independent variable. The peak area ratios must te corrected for isotopic branching probabilities and detection efficiencies. The equations are weighted using the peak area errors determined in the peak group fitting process and the relative detection efficiency for each region. If the $330-$ and 370-keV regions are not in the spectrum, then five equations are developed; if they are, then seven are developed. The matrix ALPHA formed by these equations is inverted by the subroutine MATINV. The plutonium activity ratios are calculated by multiplying the inverted matrix by the matrix BETA. The errors on the ratios are obtained from the diagonal eicments of the inverted matrix. 
The isotopic activity ratios are multiplied by corresponding half-life (see Table 2 for half-life valuus) and weignt ratios to obtain the plutonium isotopic weight ratios. The plutonium isciapic whigh: percent abundances are calculated from these ratios. This calculation requirs: $f$ vain for the ${ }^{242} \mathrm{Pu}$ abundance, which cannot be deternined by gamma-ray analysis. If the "ISt enters a nonzero value for the ${ }^{242}$ Pu abundance, then this value is used. if a zero value is entered, the ${ }^{242} \mathrm{Pu}$ abundance is calculated using an empirical algorithm based on the ${ }^{240} \mathrm{Pu}$ and ${ }^{241} \mathrm{Pu}$ abundances. The ${ }^{241} \mathrm{Pu}$ abundance must be corrected for decay since sisc* arge from the reactor. Because this decay information is not always available, the $2{ }^{1} \mathrm{Pu}$ abundance is corrected only for decay since separation from ${ }^{241} \mathrm{Am}$. This period of decay can be determined from the $241^{\text {Am-to- }}{ }^{241}$ Pu ratio 25141 . The calculated age since chemical separation from ${ }^{241}$ Am is used to partially correct the ${ }^{241} \mathrm{Pu}$ abundarice. The corrected ${ }^{241} \mathrm{Pu}-\mathrm{to}-{ }^{239} \mathrm{Pu}$ ratio $\times 4149$ and the ${ }^{240} \mathrm{Pu}-\mathrm{to}-{ }^{239} \mathrm{Pu}$ ratio $\mathrm{Z4049}$ are used to calculate the weight percent ${ }^{242} \mathrm{Pu}$ abundance P242.

After calculating the weight ratios, weight percent abundances, separation age, and attendant errors, these values are printed out. Once the program finishes printing, it returns to the beginning. updates the time/date display, and waits to start a new analysis.

\section{b. Data Analysis Subroutines}

MAXVAL -- This subroutine determines the location $L$ with the maximum value YMAX in an array $Y$. 
MINVAL -- This subroutine determines the location $L$ with the minimum value YMIN in an array $Y$.

AVE -- This subroutine determines the average value AV of those values contained in array $Y$ from array location NS to NE inclusive. The sum of these values is returned by the subroutine in SUM.

GFIT2 -- This subroutine fits the upper half of a peak with a Gaussian after removing the tailing contribution from the peak. The subroutine returns the peak position PKPOS, the peak height PKHT, and the peak width parameter ALFA. The subroutine must be provided with the position $L$ of the peak within the $Y$ array, an approximate value for ALFA, and values for the peak tail parameters EXPi (ATAll: and EXP2 (BTAlL). An error condition $\mathrm{i}, \mathrm{s}$ returned if no valid peak exists within an appropriate interval from the location $L$ or if the statistics are poor. The calling program must take appropriate action.

CTAIL -- This subroutine removes the Gausśian component from a peak and analyzes the residual for the tail parameters A and B (see Section 2 of Vol. 1 for a description of tail parameters). The natural logarithm of the positive residuals is fit to a straight line by least squares to give a tail amplitude value $A$ and a tail slope value $B$. The peak must have sufficient data in the tail for an accurate analysis.

BKGRD -- This subroutine calculates and subtracts the background distribution channel by channel from data contained in the $Y$ array. NS gives the starting location and NE the ending location of the region within the $Y$ array. The background levels on both sides of tilis region, AVBG1 and AVBG2, are provided by the calling program. The difference between these two levels is smoothed beneath the specified region and 
subtracted from the data in she region. (See the complete description of the background algorithm in Section 2 of Vol. I.) The channel data with the background subtracted are returned by the subroutine in the array YNET. NOTE that the channel data contained in the YNET array is shifted down by NS locations from the corresponding channel data in the $Y$ array.

STRIP -- This subroutine is used to strip a peak or part of a peak from channel data contained in the array $Y$. The resulting channel data are returned by the subroutine in the array. $Y$.

MATINV - This subroutine was adapted from the matrix inversion subroutine given in Ref. 10 of Vol. I. The subroutine inverts a square matrix in place and calculates its determinant. The input variables are the matrix in ARRAY and the order of the matrix NORDER. The ouput is the value of the determinant DET and the inverted matrix in ARRAY.

PUFIT -- This subroutine fits a polynomial of order NTERMS to the corrected peak areas as a function of the logarithm of the corresponding energies using a weighted least-squares technique. The peak areas are corrected for ganıma-ray branching probabilitiss. The corrected peak areas give the relative detection efficiency for the measurement at several different energies in the spectrum. Fitting these values to a polynomial gives the detection efficiency as a function of energy and allows calculation of the detection efficiency at any energy. Peak areas from ${ }^{239} \mathrm{Pu}$ and $241 \mathrm{Pu}$ gamma rays are used in this analysis; therefore, an additional term must be used in the fit to normalize the activity of the two isotopes. 
DPM -- This function routine calculates a psuedo relative detection efficiency value for

the isotope specified by the parameter $\mathrm{L}\left({ }^{239} \mathrm{Pu}\right.$ or $\left.{ }^{241} \mathrm{Pu}\right)$ at the energy (MeV) specified by $X X$. The calculation uses the polynomial coefficients determined by the $\log -\log$ fit in the subroutine PUFIT. The ratio of two values calculated by the subroutine DPM at two different energies is equivalent to the ratio of the detection efficencies at those two energies.

c. Input/Output Subroutines

RECVR -- This subroutine receives the input from the TM-25 keyboard and incerprets it. The input maybe either a numeric entry or a function command to be sent to the Silena MCA. A function command is interpreted in this subroutine and the appropriate action is carried out by issuing a corresponding command to the MCA over the parallel interface. If the BS $27 \mathrm{MCA}$ is in the surong state for the requested command, the message COMMAND ERROR is flashed on the display. The function commands work only with the Silena BS $27 / \mathrm{N}$ MCA. If the CICERO MCA is being used, the function commands from the portable microprocessar are either ignored or the message COMMAND ERROR is flashed on the display.

A numeric entry is converted into ASCIl and stored in the byte array SND. The number of digits received is returned to the calling program by $\mathrm{I}$.

This subroutine may be called to wait for input or to intercept expected input. The value of $I$ when the subroutine is called determines the option used. If $I=0$, then the subroutine waits for an entry and monitors the clock while waiting. If the clock board minute register changes while waiting, the subroutine returns to the calling program with $1=0$ to allow the calling program to update the time/date display. If the subroutine 
is called with I not equal to zero, the subroutine proceeds immediately to intercept expected input from the keyboard. This is done to avoid having a query on the display being replaced by the time/date display if the clock minute register should change before the user respo:ıds to the query.

If the START (analysis) command is intered, the SIREAD subroutine is called by this subroutine to read the data from the Silena MCA byte by byte into the array DATA. Six bytes are stored for each channel transmitted from the MCA. The subroutine RECVR converts this byte array information into floating-point values and stores them in ARRAY. This data array is pasied to the calling program by the named common DATA. This array must be located in ihe RAM part of memory. The number of channels transmittad from the Silena MCA is returned to the calling program by $I$. NOTE that the maximum number of channels that can be transferred is 2048 . The two additional ARRAY locations are for storing the spectrum number and livetime.

SIREAD -- SIREAD is a subroutine written in MACRO assembly language that performs the transfer of bytes from a Silena MCA to the portable microprocessor. The transfer is through a parallel interface in the MCA and an ADAC 1664 TTL I/O board in the portable microprocessor.

The subroutine begins by obtaining the location of the byte array where the trarismitted bytes are to be stored. It clears CHRCTR (byte counter) and then performs a test necessary only for the BS 27 MCA. This test checks to make sure that the BS 27 is in the DISPLAY mode before placing it in the STOP mode. The BS 27 MCA must be in the DISPLAY mode before sending it a STOP command, and it must be in the STOP mode before sending it REMOTE and DATA OUT commands. If the BS 27 is not in the DISPLAY mode, the subroutine returns with CHRCTR equal to zero, which is detected by the 
subroutine RECVR as an error condition. This test is not necessary for the CICERO MCA; however, these instructions do not have to be removed for the subrouting to function with the CICERO MCA.

Data transfer from the MCA begins with the stibroutine setting the MCA to REMOTE and then issuing a DATA OUT command. The subroutine then waits for the DATA READY FLAG to be set. Once the flag is set, the subroutine reads the byte (characier) at the input data register and then resets the DATA READY FLAG. The byte is compared against seven possible control characters. If it is any one of these characters, the input cyte is discarded and the subroutine calls an internal subroutine that tests whether the DATA READY FLAG is cleared. When the DATA READY FLAG is cleared, the subroutine returns to the beginning and issues a new DATA OUT command and then waits for ihe next byte from the MCA. If a legitimate character is found, the upper four bits are cleared to give the correct octal value of the decimal digit transirsitted. The result is stored in the byte buffer and the byte is counted by incrementing CHRCTR. Eight bytes are transmitted by the MCA for exch channel; two of these are control characters that are discarded.

When the end-of-spectrum character is detected, the subroutine reacis the 40 trailing control characters (rubouts) at the end of the spectrum transfer and discards them. The subroutine then returns to the calling program with the number of bytes stored in the byte array.

SEND -- This subroutine sends the ASCII characters contained in the array SND to either the 20-character display or the printer. The first character in the array indicates the device to be used and the type of output. (See subroutine listing for these characters and their interpretations.) 
A short time delay must be inserted between sending each character to the printer in order to give the printer time to check and load the character into iss buffer. If the delay is insuficient, characters will be lost. A carriage return character sent to the printer will cause the printer to print cut its buffer. Another time delay is necessary after this command to allow the orinier time to empty its buffer.

SETCLK -- This subroutine sets the TCU-50DYR clock registers from the information given by the user on the TM-25 keyboard. The subroutine uses the subroutines SENC and RECVR to interrogate the user for the time/date information. The informat on is read in ASCII from the $T M-25$ keyboard and stored in the array NBR. The DECODE function is used to convert the ASCII array to an integer value, and the function IBNBCD is used to convert the integer binary value to $\mathrm{BCD}$, which is required to set the clock registers.

CLOCK -- This subroutine reads the day IDAY, month IMO, hour IFR, and minute IMIN from the TCU-50DYR clock board in the portable microprocessor unit.

YEAR -- This subroutine reads the year from ine TCU-5DDYR ciock board CMOS RAM. This subroutine is also responsible for maintaining the psuedo year counter in the TCU-50DYR's battery-supported CMOS RAM. It is necessay to run this routine at least once a year to ensure that the year value is updated. Each time this subroutine is used, the current month is also stored in the CMOS RAM. This allows tho subroutire to determine when a new year has started. 
PORDR -- PORDR is a MACRO-11 source file that contains PSECT directives. To build a PROM-based application, certain program sections (PSECTS) must be included in the read-only memory (PROM) area. The order in which the declarations appear in the file will be the order in which the sections will be allocated in the executabie program. The MACRO-11 source file containing the desired ordering must be assembled and used as the first input file in the LINK command. 
E

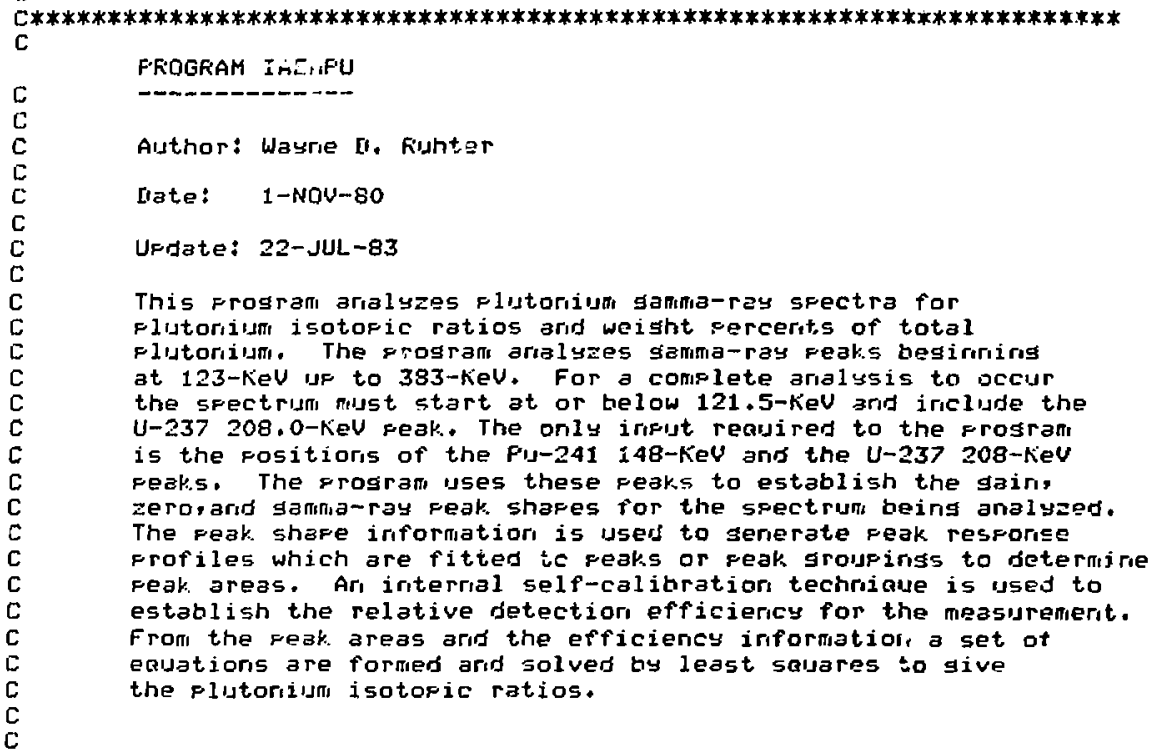
C************************************************************************************ C G LOGICAL*1 STFi (46), SNII(13), NMEF (9), IICKLF (4), F.CFLLF (4), II(2) EQUIVALENCE (II (1), SNII (12))

C

c COMMON $X, Y, A L F H A$, SUM, EKROK, YFIT, SIGMAA

C COMMON/LATA/AFFIAY (2050) !SFECTFAL IATA LOADEL INTD THIS AFFAY AKFIAY $(1)=$ SFFCTFUM $\$$; AFKAY $(2)=$ LIUETIME + UFTO 2048 IIATA CHATNELS

THE NAMEII COMMON EELOW IS NECESSAFY SO THAT THE AFFAYS MAY BE FORCEI INTO THE FROM AREA IUURING THE LINKING OFERATION. THIS MUST HE IIONE SINCE THE ARIFAY UALUES AKE LDAIIEII USING IIATA STATEMENTS.

\section{COMMON/FUFE/STR, LICRLF , FCFLF , ENG, ENSTCH , ENECH, NEG1 , NHS2}

IIMENSION ENSTCH( $(9), E N E C H(9), N E G 1(9), \operatorname{NEG} 2(9), N X F L G(8), S T H(2)$, 1 KATIO(13), SHAFC (2), NKEF (2), KEFCH(2), ENG (37), FKFOS 8 ), FKHT (8), 2 FT $(3), A X(5), \operatorname{SUM}(6), A L F H A(6,6), C(2), A K E A(37)$, YFIT $(6)$, SIGMAA $(6)$, 3 ERF( 37$), X(6), Y(210), F(7,4)$;WTF(7), BETA $(4)$, FAT $(4), E R F O F(6)$ WINLIOW IIUKING ANALYIS MUST EE HIG ENOUGH TO HANILE 18.7/GAIN +10 IIATA CHANNELS. 
c

C

IIOUELE F'KECISION SUM,ALFHA

c

C

C.

C

c

c

C

C

C

C

C

C

C

C

C

C

C

C

C

C

C

C

C

C

c

C

C

C

C

C

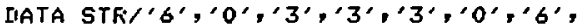

THE EYTE STRING EELOW CONTAINS INFORMATION NEEIEI IN FITTING EACH FEAK OK F'EAK GROUFING. THE FIRST VALUE ON EACH LINE INIICATES THE NUMEER OF FEAKS IN THE GKOUF. FOR INSTANCE THE FIFST 6 ON THE FIFST LINE INUICATES THERE AKE \& FEAKS IN THE FIFST GROUF. THE FEMAINING UALUES IN THE LINE INIICATE WHETHER THE FEAK HEIGHT IS A FREE FARAMETER FUR THAT PEAK OF IF IT IS FIXEI FELATIVE TO ANOTHER PEAK. IF THE VALUE IS O OF IS EQUAL TO THE NUMEEF OF PEAKS IN THE GKOUF, THE FEAK HEIGHT IS A FFEE FARAMETER, ANY OTHER VALUE INDICATES THAT FEAK IS FIXEU KELATIUE TO THE FFEE FEAK INIICATE! BY THAT VALUE, FOF INSTANCE, IN THE FIRST LINE THE VALUE 3 FOR THE SECOND, THIFI, ANI FIJUETH F'EAK INIICATES THAT THESE FEAKS AFE FIXEN RELATIVE TO THE THIFU FKEE FEAK IN THE GROUF WHICH IN THIS CASE IS THE LAST FEAK. THE FEAK WHICH HAS A VALUE EQUAL TD THE NUMEEF OF F'EAKS IN THE GROUF IS THE FEAK TO WHICH THE FOSITIONS OF ALi. THE OTHER PEAKS ARE FIXEI TO, i.e., IT IS THE FOSITION FEFERENCE FOK ALL OF THE OTHEF FEAKS IN THE GROUF.

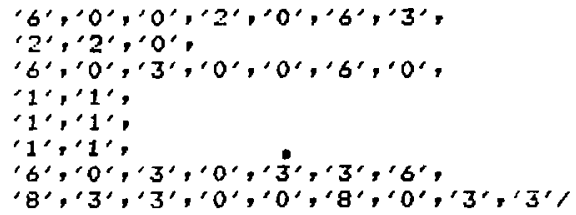

THE STRINGS EELOW GENEFIATE A CARKIAGE RETURN ANII LINE FEEI OM THE LIEUICES INDICATEL.

IIATA IICKLLF/"104,"15,"12,"40/ !IISFLAY

IIATA F'CFLF $/ 40,15, " 12, " 40 /$ IFFINTEF

ENFFGIES (KEV) OF FEAKS TO FE AHALYZEI 
IIATA ENG/122,926,123.62,124,51,125.21,125.293,129.294,

$1141.567,144.211,146.077,146.557,148.567,150.11$,

$2152.68,154.2$,

$3159.955,160.19,160.308,161,482,164.597,165.93$,

4185.72 ,

$5203,5,37$,

$6208 .$,

$7332.385,332,853,335,43,336,104,341,517,345.011$,

$8367.050,368.546,368.603,370.933,375.042 .376 .59$,

c

$9380,166,382.74 /$

START FOSITIONS FOF EACH FEAK OF F'EAK GROUF-ING IN KEU

IJATA ENSTCH/121,9,141,,151.7,159.2,184,.202.7,206.3,

$1331,, 366.1$

$\mathrm{C}$
$\mathrm{C}$
$\mathrm{C}$

ENIING FOSITIONS FOF EACH FEAK OF F'EAK GROUF'IHG IN KEU

[IATA ENECH/130.6,150.8,154.7,166.4,187,.204.7,211,,

$1347.14,384,68 /$

C

la

NUMEEF OF CHANNELS USEI TO JIETEEMINE THE FACKGKOUNII IN

FFIONT OF EACH GFIOUF'.

IIATA NEG1/3,3,5,4,5,5,4,5,5/

C

C

C

C

c

c

$\mathrm{C}$

C

C

C

MUMHEF OF CHANRELS USEII TO IIETERIMINE THE BACKGKOUNII

EEHINI EACH GROUF' .

LATA NEG2 $/ 10,3,3,7,5,3,10,5,5 /$

INTENSITY RATIOS FOR INLICATELI FEAKS

FAATIO $(1)=0,00315$

FiATIO $(2)=0.00993$

FATIO $(3)=0.00923$

FATIO $(4)=.42$

FATIÚ (5) $=.1605$

FATIO $(6)=.0517$

FATIO $(7)=0.905$

FAT IO $(B)=0.20 .3$

RATIO $(9)=0.1184$

FATIO $(10)=.055095$

FATIO $(11)=.057515$

FATIO $(12)=.19426$

RATIO $(\$ 3)=.16496$

$! 123.62 / 129.294$
$! 124.51 / 129.294$
$! 125.21 / 129.294$
$! 146.1 / 144.2$
$! 150.1 / 146.6$
$! 160.2 / 161.5$
$! 332.838 / 345.01$
$! 336.107 / 345.01$
$! 341.51 / 345.014$
$! 367.050 / 375.042$
$! 368.55 / 375.042$
$! 380.166 / 375.042$
$! 382.751 / 375.042$

REFEFENCE FEAK ENERGIES TO ESTAELISH GAIN, ZEFIO. ANL FEAK SHAFES

STII $(1)=17$. 9.567

STIU $(2)=208$. 


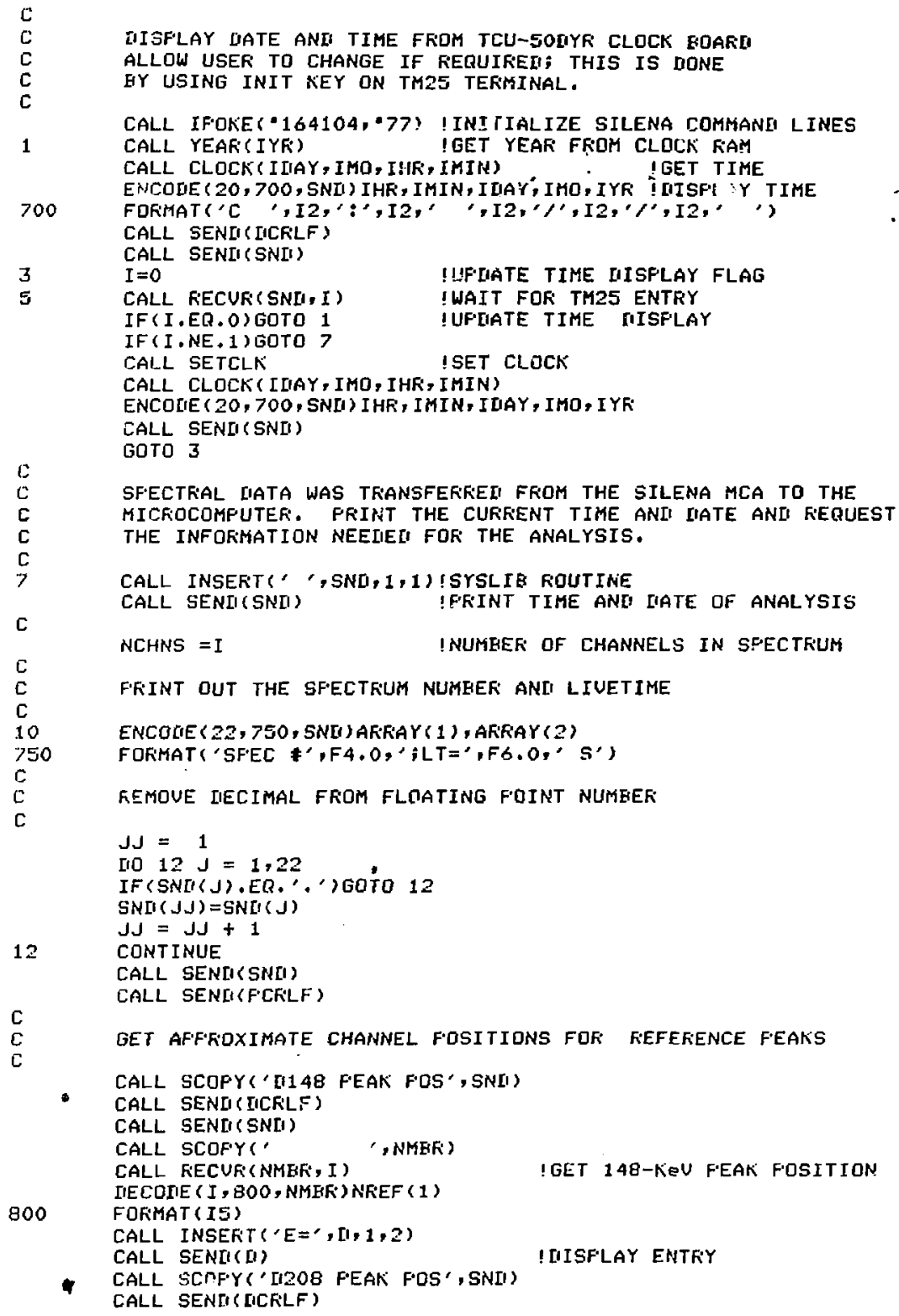


CALL SENIISNII)

CALL RECUR (NMBŔ, I)

UIECCIIE ( $I, 800$, NMEF')NFEF (2)

CALL INSEKT (' $E=', I 1,1,2$ )

CALL SEKIT(II)
!GET 208-KeV FEAK FOSITION

IIISFLAY ENTRY c

C

C

C

803

804

C

C

C

C

15

C

C

c

C

C

C

C

C

C

C

C

GET F'U-242 WT. \# ANI EKFIOF FKOM OFEK'ATOF, IF OFEKATOK ENTERS A ZEKO VALUE FOK F'U-242, THE PU-242 WT. \% IS CalCuLATEI.

CALL SCOFY('IUT \% FU-242 ', SND)

CALL SENII (ICELF)

CALL SENLISSNLI)

CALL SCOFY(' ',NMEF')

CALL FECUF(NMEF, I) IGET FU-242 WT, \%

DECDIE ( $I, 803$, NMER $) F 242$

FOKMAT ( 65,0$)$

CALL INSEKT ('E=', II, 1,2)

CALL SENIIII)

IF $(F: 242, E Q+0) G 0 T 015$

CALL SCDF'Y ('IIF'U-242\% EFF', SNII)

CALL SENII(IICFILF)

CALL SENEISSNE)

CALL SCDFY', 'NMER')

CALL FECUR (NMEF', I)

[IECOIIE ( I, 803, NMER ) FE2 42

!GET Z EKKOK DN F'U-242 WT.

ENCODE $(7,804$, IN)FE242

FOFIMAT ('E $\left.={ }^{\prime}, F E+2\right)$

CALL SENII(II)

$\mathrm{FE} 242=\mathrm{F} E 242 * \mathrm{~F} 242 / 100$.

! IISF'LAY ENTFY

CALCULATE AF'FOXIMATE GAIN AND ZERO FFOM FEAK FOSITIONS

ENTEF'EI BY THE OF'ER'ATOK'.

GAIN=(STLI(2)-STII(1))/(NFEF(2)-NFEF(1)) IAFFFOXIMATE GAIN

ZEFO $=S T[1(2)-N K E F(2) * G A I N$

! AFF'ROXIMATE TERO VALUE

AF'ROXIMATE SHAF'E CONSTANTS FOR FWHM ANII TAIL FARAMETERS

SHAF'C $(1)=0.2$ !F'EAK SHAFE F.AR'AMETEFS FOK FULL -WIIITH

SHAF' $(2)=0.0017$ ! THIS UALUE IS FIXEI

ATAIL $=.058$

BTAIL $=2$. *GAIN !THIS IS AN AFFFOXIMATE VALUE FOR GAIN

INITIALIZE COUNTERS ANI FOINTEFS

NGFF $=9$

$N F \cdot K 5=0$

NSTRF'T $=1$

NF'ATF'T $=1$

$A 345=0$.

! NUMEEF' OF GROUF'S

I FEAK COUNTEK

ISTKING FOINTEF

IFATIO FOINTEK:

! INITIALIZE ; USEI FOK FLAG LATEK

USING REFEKENCE FEAK'S ESTABLISH GAIN. ZEKO, ANL FEAK SHAFE

F'AFAAMETEK'S FOR GIUEN SFECTKUM. TWO F.ASSES ARE MALE RECAUSE

OF THE AF'F'RXIMATE ESTIMATES OF F'AF'AMETER'S USEII ON THE FIRST FASS.

IIO $40 \mathrm{JJ}=1,2$ !IO THIS TWICE

[10 $30 \mathrm{~J}=1,2$

IST-IVT'EF(J)-30 !STAFTING CHANNEL FOR FEEFEKENCE FEAK FEGION $S T=I S T$ 
DO $20 K=1,60$ ! TKANSFEK DATA INTO WORKING AFRAY $Y(K)=A F F A Y(I S T+K)$

GET MAXIMUM AND MINIMUM UALUES IN FEAK REGION AND CHECK TO MAKE SURE VALII FEAK EXISTS IN REGION.

$I S T=1$

CALL MAXUAL (IST, 60, JFK, YMAX, Y)

CALL MINUAL $(1, J F K, M S, C 1, Y)$

CALL MINUAL (JFK, $58, M E, C 2, Y)$

CALL AUE (MS, ME, YSUM, AU, Y)

C

C

C

C

c

C

C

C

C

C

C

C

C

C.

C

C

C

C

C

C.

30

c

C

YSUM IS THE GROSS NUMEER OF COUNTS IN THE REFEFENCE FEAK

IS IIATA IN THE SFECIFIEI REGION STATISTICALLY SIGNIFICANT?

IF ( (YMAX-C1) , GT , 4, *SRRT (YMAX)) GOTO 22

CALL SCOFY('FEAII FEAK FOSITION',SNII)

CALL SENI (IICKLLF)

CALL SENIISNI) !SENI MESSAGE THAT a UALIII FEAK WAS NOT FOUNI GOTO 5

SUETKACT OUT RACKGROUNI FROM REFEF.ENCE FEAKS USING A SMOOTHED STEF EENEATH THE FEAK.

$Y S=0$.

IIEG=C2-C1 !IIFFEFENCE BETWEEN THE FRONT ANII BACK EKGS,

DO $25 \mathrm{I}=\mathrm{MS}, \mathrm{ME}$

$Y S=Y S+Y(I) \quad$ IFAKTIAL SUM OF FEAK

$Y(I)=Y(I)-C 1-D E G * Y S / Y S U M$

DETEKIMINE THE FEAK CHANNEL LOCATIONS AND SHAFES GF THE REFERENCE FEAKS

GSR=GAIN*GAIN

$S G=S H A F C(1) / G S Q+S H A F C(2) *(S T / G A I N+Z E F O / G S R)+0.462$

SG = THE (FULL-WIETTH-HALF-MAXIMUM IN CHANNELS)**2

ALFA $=-2.7726 / 5 G$ !AFF'ROXIMATE F'EAK WIITH F'AKAMETEK

GET F'EAK CHANNEL FOSITION ANI WIITTH FARAMETEK ALFA

TEST EFROR FLAG; IT WILL EE SET TO -1 IF FEAK IS NOT

FOUNII OF IIOES NOT AFFEAR TO FE GAUSSIAN.

CALL GFIT2 (JFK, ALFA, ATAIL, ETAIL, FKFS, F KT, EKRF, $Y$ )

IF (ERKF, ER \& -1) GOTO 21

$C(J)=A L F A$

FEF CH $(J)=S T+F \cdot K F S$

EET PEAK TAILING F'ARAMETEKS ATAIL ANI BTAIL. AN AFF'ROXIMATE VALUE MUST RE SEMT FOK ATAIL IN THE CALL.

CALL CTAIL (MS, ME, FKFS, FKT, ALFA, ATAIL, ETAIL, Y)

CONTINUE

CALCULATE NEW GAIN ANI ZERO FROM IIETERMINEII REFERENCE FEAK FOSITIONS 


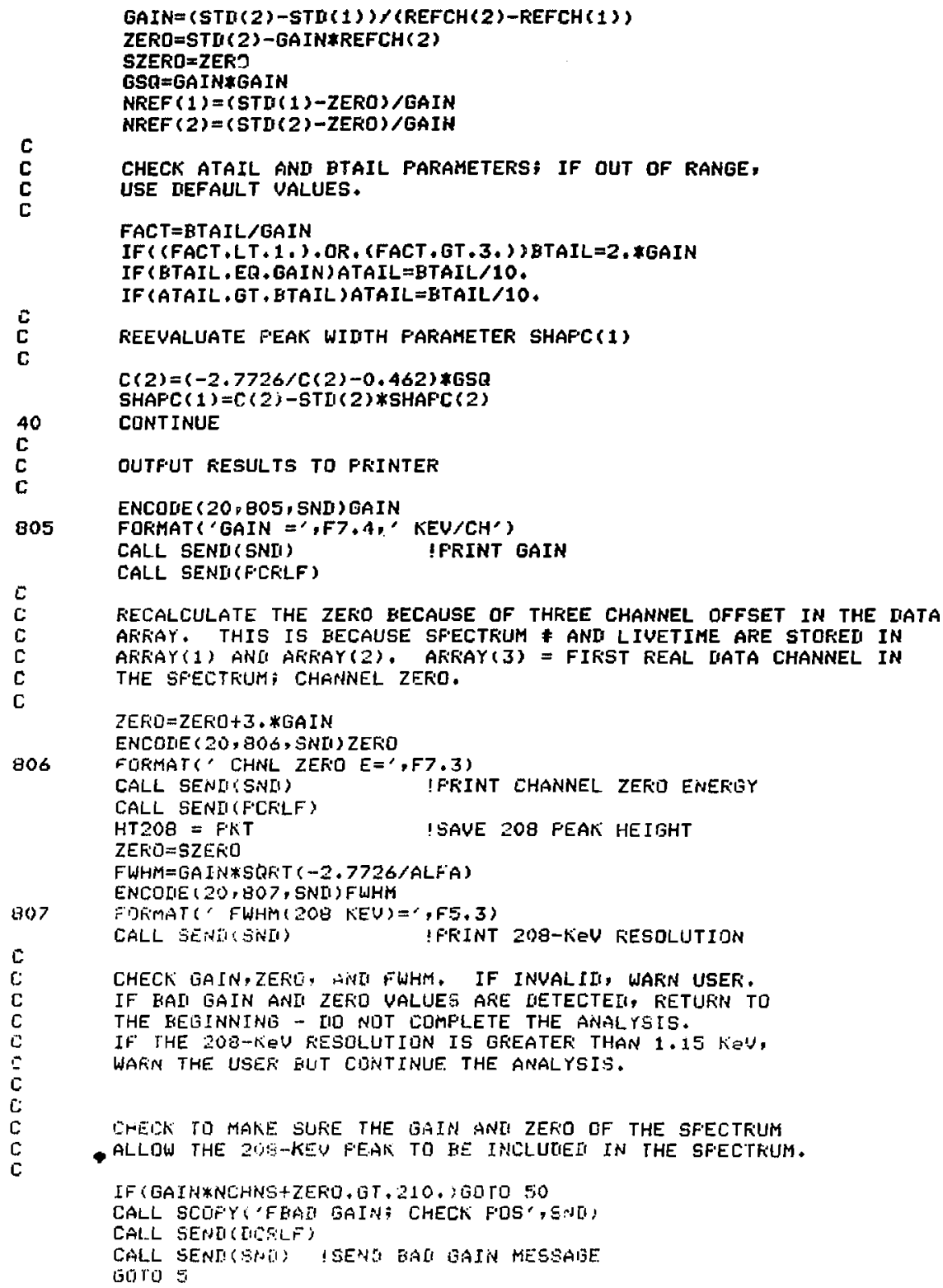

C

C

$\stackrel{c}{\mathbf{c}}$

40

C

C

c

805

$\varepsilon$

$c$

C

C

C

C

807

c

c

C

C

$\mathrm{c}$

5

C

$\mathrm{C}$

C

C

CHECK ATAIL AND ETAIL PARAMETERS; IF OUT OF RANGE, USE DEFAULT UALUES.

FACT=BTAIL/GAIN

IF ( (FACT, LT , 1, ) , OR, (FACT, GT , 3, ) ) ETAIL=2, \$GAIN

IF ( BTAIL, EQ. GAIN) ATAIL=BTAIL $/ 10$.

IF (ATAIL, GT , BTAIL) ATAIL=ETAIL/10.

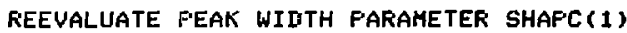

$C(2)=(-2.7726 / C(2)-0.462) * G S Q$

$\operatorname{SHAFC}(1)=C(2)-S T I(2) * \operatorname{SHAFC}(2)$

CONT INUE

OUTFUT FESULTS TO PKINTER

ENCOLE (20,805, SND) GAIN

FORMAT ('GAIN $=$ ',F 7,4 , KEU/CH')

CALL SENL(SNII) IFRINT GAIN

CALL SENI (F.CRLF)

RECALCULATE THE ZEKO EECAUSE OF THREE CHANNEL OFFSET IN THE IATA AFRFAY. THIS IS EECAUSE SFECTRUM * AND LIUETIME ARE STOFEI IN AFF'AY (1) AN[I AFIFAY (2). AFFAY (3) = FIKST REAL IIATA CHANNEL IN THE SFECTFUM; CHANNEL ZEFID.

ZEFIO $=Z E F O+3 \cdot * G A I N$

ENCOIE ( 20,806 , SNL)ZERTO

FORMAT(' CHNL ZEFIO E=',F7.3)

CALL SENIISNII)

! FRINT CHANNEL ZEFIO ENEKGYY

CALL SENII (F'CFLF)

HT208 $=F K T$

!SAVE 208 FEAK HEIGHT

$Z E F O=S Z E F T$

FWHM=GAIN*SRF T $(-2.7726 / A L F A)$

ENCODE ( $20,807,5 N I) F$ WHM

FITRMAT( FWHM $(208 K E V)=\cdot F 5+3)$

CALL SEITIISTII)

IFRINT 2Og-KIEV RESOLUTION

CHECK GAIN,ZEFI, SNT FWHM, IF INUALII, WARN USER, IF EAII GAIN ANI ZEFD VALUES ARE DETECTEI, RETURI TO THE KEIINNING - IIO NDT COMFLETE THE ANALYSIS.

IF THE 203-KIEU RESOLUTION IS GFEATEK THAN 1.15 Ked, WAFIN THE USER EUT CONTINUE. THE ANALYSIS.

CHEIKK TO MAKE SURE THE GAIM ANE ZEFO OF THE SFECTFUM - ALLOW THE 2US-KEU FEARK TO BE INLLUUEII IN THE SFECTKUM.

IF IGAIH*NCHNS+ZERO.GT,210, :GOTO 50

CALL SCUPYY'FEAD SAIN; CHECK FOS', SNU,

CALL SENIISEOELF;

CALL SENI!SSTII) ISEAT EALI GAIN MESSAIJE.

Goro 5 


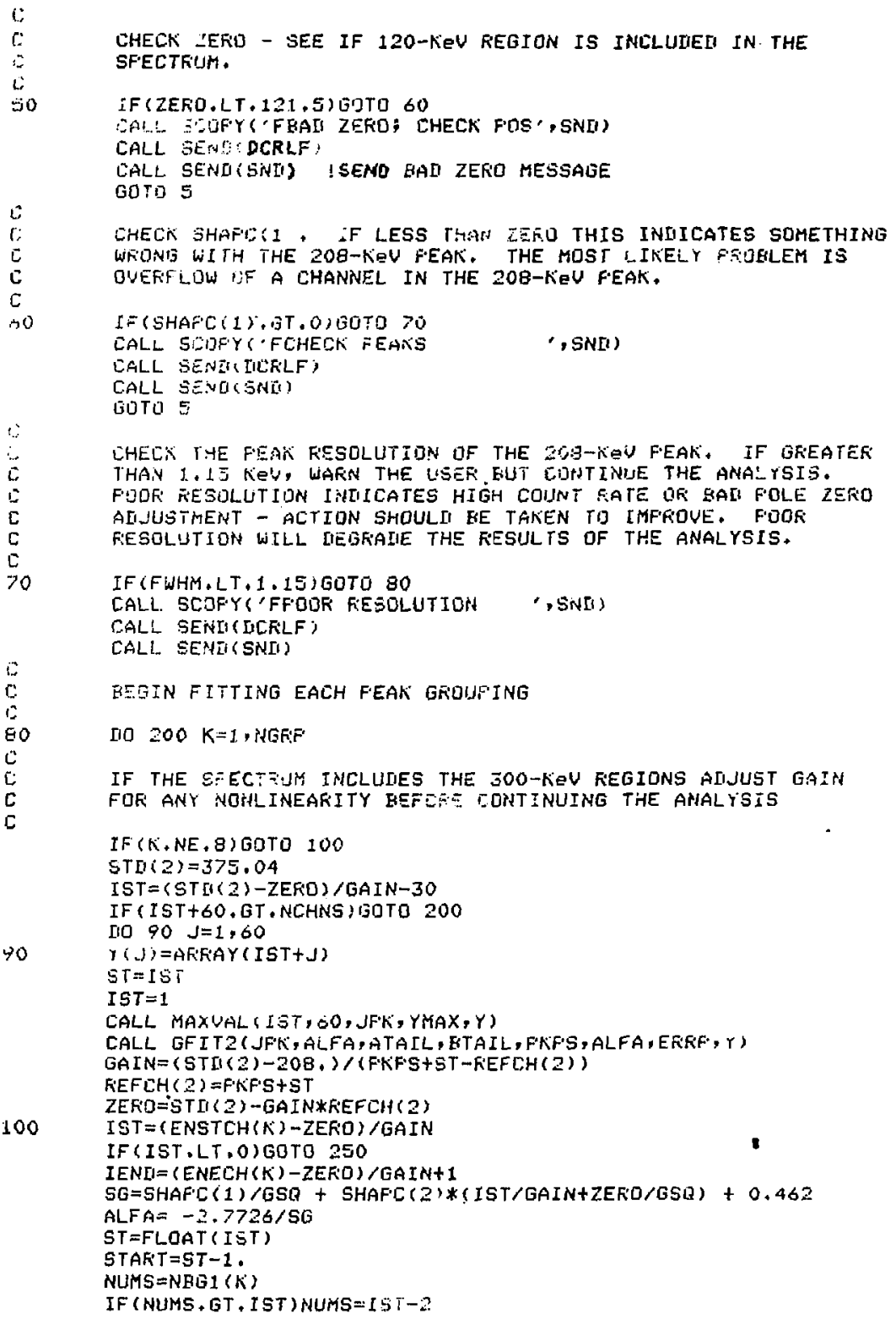




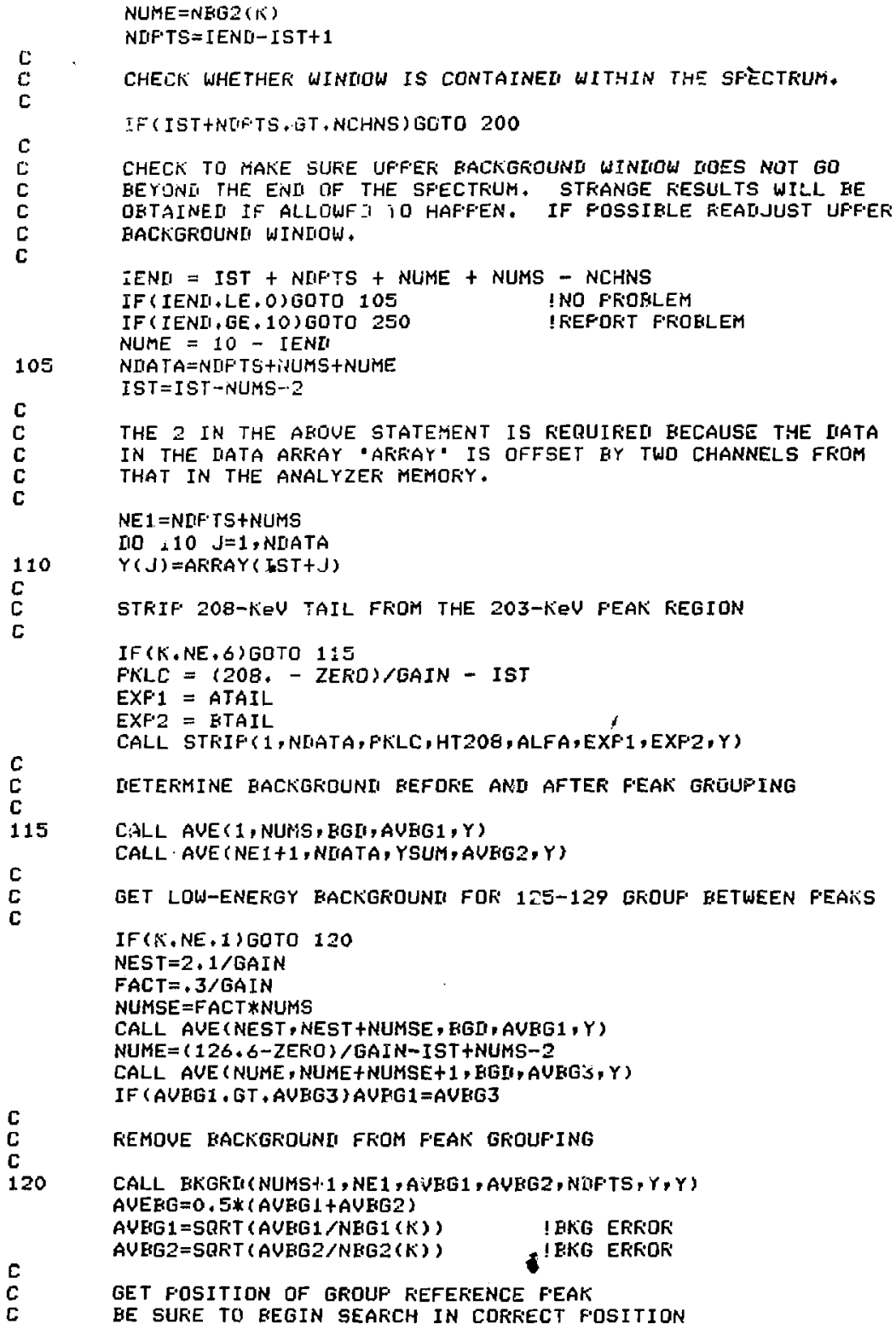


C

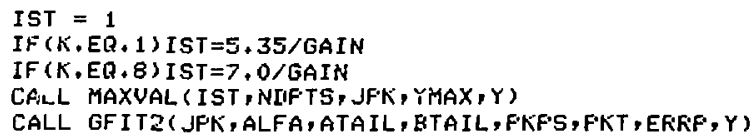

C

C

C

HAUING IIETERMINED FOSITION OF REFEKENCE FEAK FFF GFOUF'ING FECALCULATE THE GAIN IN ITS LDCAL REGION EASEII ON ITS F'OSITION FELATIUE TO THE 208-KEV F'EAK

IF ( (K.EQ. ᄀ). OK. :KK.EQ.,$))$ GOTO 145

SGAIN= (REFEN-STII(2) $) /\left(F^{\prime} K^{\prime} F\right.$ S S STAKT-1 • -FEFCH(2) $)$

CALCULATE THE FOSITIONS OF ALL FEAKS IN THE GROUPING

F'ELATIUE TO THE REFERENCE F'EAK FOK THE GROUF'.

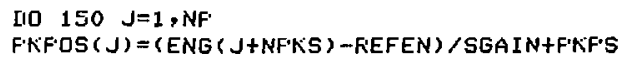

GENERATE FEAK RESFONSE F'ROFILE FOR FEAK GROUFING ANII STOKE IN THE "AX' AFIFIAY.

INO $170 \quad I=1, N$ LF'TS

$W T=1.0 /(Y(I)+A V E E G)$

$X I=I$

$L=1$

IIO $152 \mathrm{~J}=1,5$

$152 \quad A \times(J)=0$.

IIO $160 \mathrm{JJ}=1$, NF

IILTAX $=X I-F$ KF'OS $(J J)$

IILXSQ $=$ ILT TAX*IL TAX 


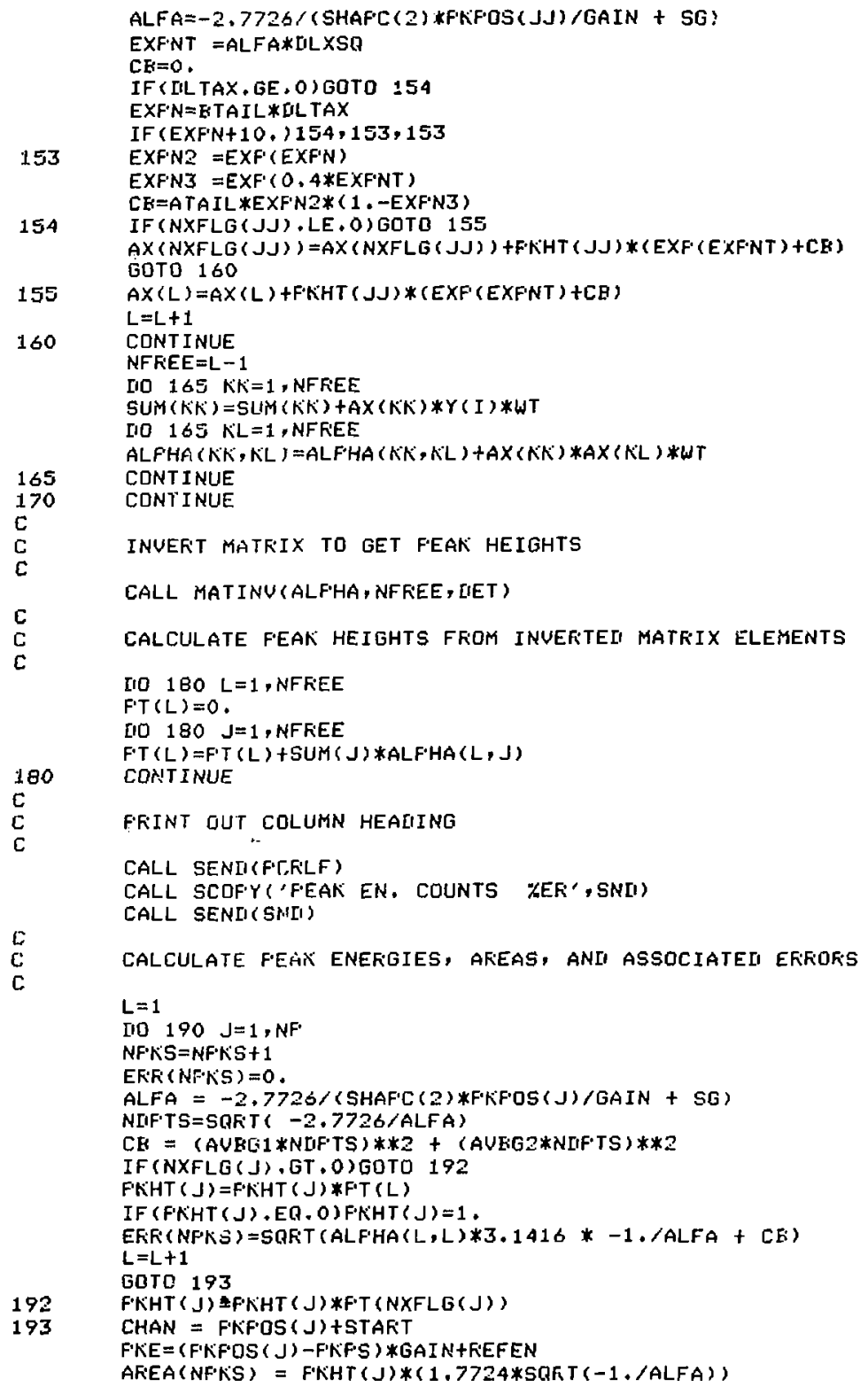


IF (EFF (NF'KS), ER, O)GOTO 195

IF (AFEA (NFKS) , LE. O)GDTO 194

$E F F(N F$ 'NS) $=100$, * EFF (NFK'S) /AKEA (NPKS)

$194 \operatorname{IF}(A R E A(N F K S), L E+3, * S R K T$ (CE) ) AFEA (NFKS) $=0$.

C

$\mathrm{C}$

F'RINT OUT FEAK ENERGIES, AKEAS ANI EKROKS

C

195 ENCOLIE (20, $\$ 30$, SiNLI) FKE, AFEA (NFKS), ERF (NFKS)

C

IF FEAK HEIGHT WAS FIXEII RELATIUE TO ANOTHER FEAK IN THE GF'QUF' LABEL IT AS SUCH

C

C

IF (EFF' (NF'KS) ,EQ, 0) CALL INSERT('FIXI', SNII, 17,4)

FOFIMAT (F6, 2,1X,FB, 0,F5,1)

CALL SENII(SNII)

200 CDNTINLE

C

C:

C

C

IIETEKMINE IF THE FIRST 7 FEAKS/FEAK GFOUF'INGS WEKE ANALYZEI, IF NOT, FEF'OKT F'ROBLEM ANII STOF' THE AHALYSIS.

[F(K゙,GE.7)GOTO 251

CALL SCGFY('FHALI GAIN OF' ZEFO 'SNEI)

CALL SENTI(IICKLLF)

CALL SENL (SNII)

GOTO 5

c

c

C

C

$\mathrm{C}$

251

IIIUILE SELECTEII F'EAK AFEAS EY AFFFOFFIATE FFANCHING RATIOS TO GIVE IISINTEGRATIONS. USE THIS INFORNATION TO IIETERMINE RELATIUE IIETECTION EFFICIENCY FOI: SAMFLE.

NGRF $=4 \quad ! \neq$ OF FEAKS TO HE USELI

$\mathrm{NF}=4$

! \& OF F'AFAMETERS TO USE IM THE FIT

$Y S=.001$

!USE TO CONUERT ENEFIGIES TO MeU

C

$X(1)=A L O G(E N G(6) * Y S) \quad$ IFU-239 129.3-KeV

$Y(1)=A 129 / 6+26 E-05$

EFFOR ( 1$)=E F_{1} 129$

$X(2)=A L O G(E N G(19) * Y S) \quad$ IFU-241 $164.6-K e U$

$Y(2)=A 165 / 4+64 E-07$

$\operatorname{EFFOF}(2)=E F_{1} 165$

$X(3)=A L O G(E N G(22) * Y S) \quad$ !FU-239 203.6-KEV

$Y(3)=A 203 / 5 \cdot 6 E-06$

EKF'OFi ( 3 ) =EF:203

$X(4)=A L O G(E N G(23) * Y 5) \quad$ IFU-241 208.0-KEU

$Y(4)=A 20 B / 5 \cdot 33 E-06$

$\operatorname{EKROR}(4)=E F: 208$

c

INCLULIE THE 3O0-KE\& FEAK INFOFMATION IF GROUFS WEFE ANALYZEU

IF $(A 345, E Q$. O) G0T0 255

$X(5)=A L O G$ (ENG $(25) * Y S) \quad$ IFU-239 345.0-KeU

$Y(5)=A 345 / 5.59 E-06$

EFFIOR (5) $=E R: 345$

$X(6)=A L O U$ (ENG (34)*YS) IF.U-239 375.0-KeV

$Y(6)=A 375 / 1.55 E-05$

EFIFIOK $(6)=E K 375$

C

NGFF $=6$

NF' $=5$
!\#OF FEAKS TO BE USEE; A345 NONZEKD

! \$ OF FFEE FAFAMETEFS TO BE USEII IN FIT

c 


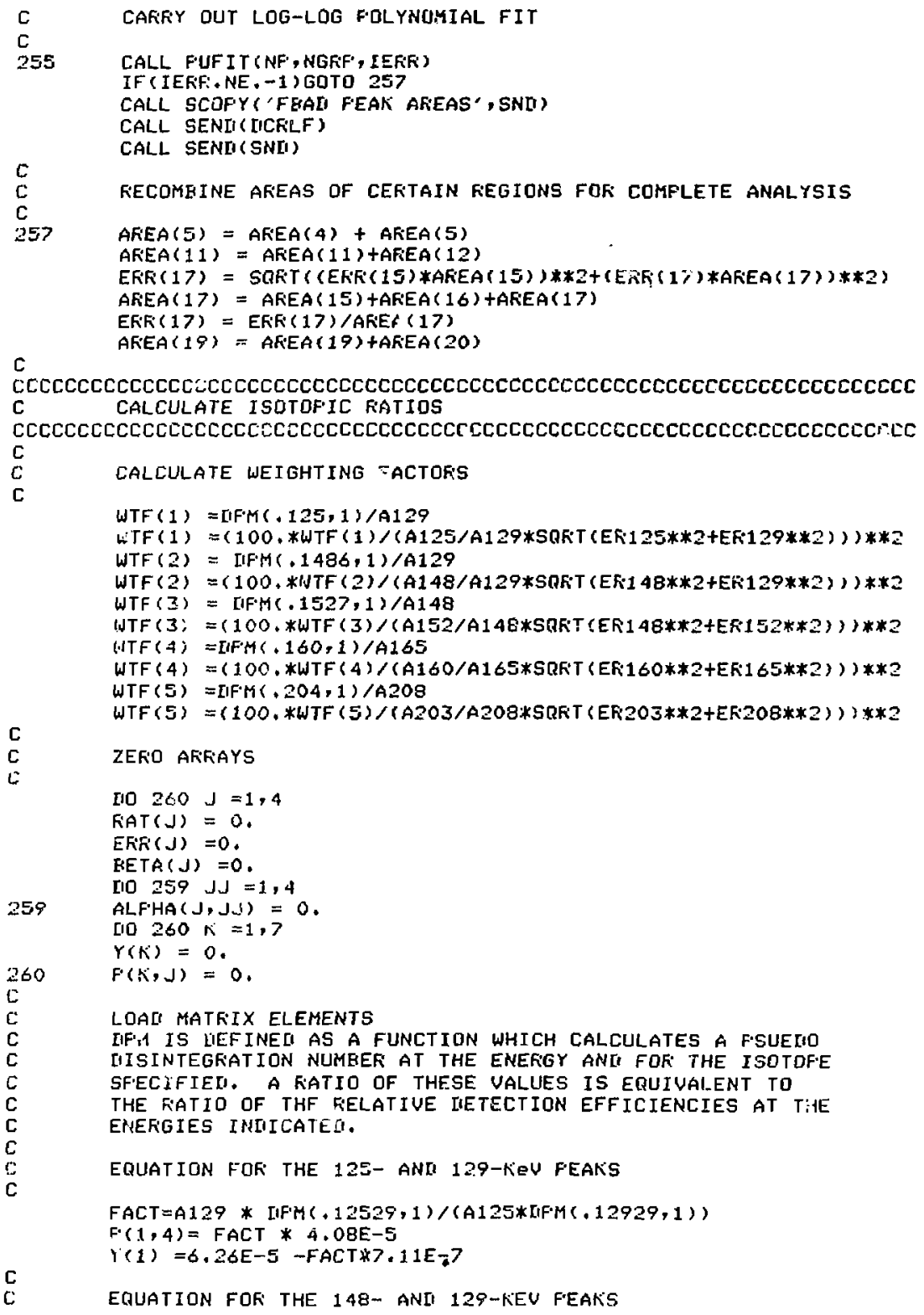


$P(3,1)=9.32 E-6$

FACT $=A 152$ ADFM $(.14857,2) /(A 148 * \operatorname{IIFM}(.1527,2))$

$F(3,3)=-F A C T * 1,90 E-6$

$P(3,4)=-F A C T * 7.40 E-7$

c

EQUATION FOR THE 160-KeV PEAK GKOUFING ANI THE 165-KEV FEAK

c

C

$F(4,2)=-4,02 E-6$

$F A C T=A 160 * D F M(.1646,2) /(A 165 * D F H(, 160,2))$

$\mathrm{F}(4,3)=$ FACT $* 4.63 E-7-6.4 E-8$

$P(4,4)=F A C T * 8.99 E-7 \quad 16.67 E-7+2.32 E-7$

$Y(4)=7,0 E-3$

D

ERUATION FOK THE 203- ANL 208-KEV FEAKS

$F(5,3)=A 203 * \operatorname{LIFM}(.208,2) /(A 208 * \operatorname{IIPH}(.2036,2))$

$F(5,4)=P(5,3) * 7.91 E-6$

$F(5,3)=F(5,3) * 5.33 E-6$

$Y(5)=5.6 E-6$

C

C

C

C

c

c

C

C

INCLUUT, INFORMATION FFIOM THE 300-KEV FEAKS IF THEY ARE

FRESENT IN THE SFECTRUM.

IF (A345, ER . 0) GOTO 262

RECOMEINE AREAS HEFORE ANALYZING

AREA (24) = AREA (24)+AREA (25)+AREA (26)+AKEA(27)

$A F^{\prime} E A(29)=A R E A(28)+A K E A(29)$

$A F E A(33)=A K E A(32)+A K E A(33)$

$A R E A(34)=A R E A(34)+A F E A(35)$

C

WTF $(6)=$ IIFH $(.333,1) / A 345$

WTF $(6)=(100, *$ UTF $(6) /(A 332 / A 345 *$ SRRT $(E R 332 * * 2+E R 345 * * 2))) * * 2$

WTF $(7)=$ IIFM $(.370,1) / A 375$

c

WTF $(7)=(100, * W T F(7) /(A 370 / A 375 *$ SRKT $(E R 370 * * 2+E R 375 * * 2))) * * 2$

C

ERUATION FOR THE 330-KEV F'EAK GROUFING

FACT $=A 345 * \operatorname{IFM}(.333,2) /(A 332 * \operatorname{IF} M(.345,2))$

$F(6,3)=$ FACT $\$ 3.219 E-7 \quad ! 2.9 B E-7+2.39 E-8$

$F(6,4)=$ FACT *6.45E-D ! $1.49 E-6+4.96 \mathrm{E}-6$

$c$

$Y(6)=6.62 E-7+5.59 E-6-$ FACT* $6.054 E-6$

C

EQUATTINN FOR THE 370-KEU PEAK GKOUFING

$F A C T=A 375 * \operatorname{IFM}(.370,1) /(A 370 * \operatorname{IF} M(.375,1))$

$F(7,3)=$ FACT $* 3,76 E-8$

! $1.05 E-8+2.71 E-8$

$F(7,4)=$ FACT $* 2.693 E-6-1.38 E-6$

c $Y(7)=1.55 E-5$

C SETUF MATRIX FOF ISOTOPIC RATIOS

C

262 IIO $265 I=1, N G K F+1$ 
[10 $265 \mathrm{~J}=1,4$

$\operatorname{EETA}(J)=\operatorname{EETA}(J)+P(I, J) * Y(I) * W T F(I)$

IIO $265 K=1,4$

265 ALFHA $(J, K)=\operatorname{ALFHA}(J, K)+F(I, J) * F(I, K) * W T F(I)$

C

c

INUEFT MATRIX TO GET ISOTOFIC RATIOS

CALL MATINU(ALF'HA, 4, IIET)

C

CALCULATE ISOTOFIC FATIOS ANII ERFORS FROM THE INUERTED MATRIX ELEMENTS

C

$\mathrm{C}$

[IO $270 \mathrm{~J}=1,4$

IIO $270 K=1,4$

ERFi $(J)=\operatorname{SOFTT}(A L F \cdot H A(J, J))$

270

FAT $(J)=$ FIAT $(J)+$ BETA(K)*ALFHA $(J, K)$

$\mathrm{C}$

C

C

COFKECT KATIOS FOK HALF-LIVES ANI MASS IIFFERENCES

$Z 4849=$ FAT ( 1$) * .003628$

$E Z 4849=\operatorname{EKF}(1) * .003628$

$Z 4049=F A T(2) * .27252$

$E Z 4049=\operatorname{EKF}(2) * .27252$

$Z 4149=$ KAT $(3) * .0006009$

$E Z 4149=E F F(3) * .0006009$

$Z 5141=$ FAT $(4) * 1, / Z 4149 * .018025$

$E Z 5141=E F F(4) * 1, / Z 4149 * .018025$

$E Z 5141=Z 5141 * S Q F T((E Z 5141 / Z 5141) * * 2+(E Z 4149 / Z 4149) * * 2)$

$Z 2549=A 185 * 7.038 E 0 B /(.561 * \operatorname{IJPM}(.186,1) * 24119$,

EZ2549 = SAFT (EF1BE**2 + EF203**2)*Z2549/100.

C

c

c

Calculate time SINCE SEFAKation of aM-241 gased ON the

AM-241/FU-241 FIATIO.

FUAGE $=$ ALOG $(0.96694 \times 25141+1,2 / 1.2793 E-04$

EFUAGE $=(.96694 * E 25141) /(1 .+.96694 * Z 51.41) * 1.2793 E-04)$

C

c

IJETEFIMINE FU-242 AEUNLANCE ANU CALCULATE WEIGHT

FEFCENT FOF EACH FU ISOTOFE. CORRECT FU-241 ABUNLANCE

FOK IIECAY SINCE SEFAFATION. NOTE: THIS COKFECTION IS

NOT COMFLETE SINCE IT IGNOKES COOLING TIME.

$X 4149=Z 4149 /$ XXF $^{\prime}(-F \cdot U A G E * 1.322 E-4)$

C

C

C

CALCULATE FU-242 aEUNRANCE BaseI ON Fi. GUNNINK GLGOFITHM

IF (F'242, NE . 0) GOTO 280

$F 242=52, * Z 4049 * X 4149$

$\mathrm{F} E 242=\mathrm{F}^{2} 242$

$2 \mathrm{BO} \quad \mathrm{CE}=1+\mathrm{Z} 4849+Z 4049+Z 4149$

$F^{\prime} 239=(100 .-F \cdot 242) / C B$

PE239=SQFT (EZ4849**2+EZ4049**2+EZ4149**2)*F'239

$F \cdot 239=S Q R T\left((F \cdot C 239 / C E) * * 2+\left(F^{\prime} E 242 /\left(100,-F^{\prime} 242\right)\right) * * 2\right)$

$C E=(F \cdot E 239 / F 239) * 2$

C

CALCULATE FLUTONIUM ISOTOFIC WT \% aEUNuances

FU-238 WT. $\%$ 
C

$c$

$F \cdot 238=Z 4849 * F \cdot 239$

F'E238=SAFT $((E Z 4849 / Z 4849) * * 2+C E) * F^{\prime} 238$

C

C

C

C

C

C

C

C

$\mathrm{C}$

$\mathrm{C}$

$\mathrm{C}$

FU-240 WT, \%

$F \cdot 240=24049 * F=239$

FE240 $=S Q F T$ ( (EZ4049/Z4049)**2+CE)*F 240

FU-241 WT, \%

$F 241=Z 4149 * F 237$

FE241 =SQRT $($ (EZ4149/Z4i49)**2+CE)*F241

AM-241 TO IOTAL F'LUTONIUM

AM241=Z5141*F'241

EM241 =SQRT $((E Z 5141 / Z 5141) * * 2+(F \cdot E 241 / F \cdot 241) * * 2) * A M 241$

F.RINT DUT THE ISOTOFIC FATIOS ANII THE ISOTOF'IC

WE IGHT FFËICENTS

CALL SENI(FCFLF)

ENCOIIE ( 20,900, SN[1) Z4849

$900 \quad$ FOFIMT $\left(' 238 F^{\prime} U / 239 F^{\prime} U{ }^{\prime}, F 8,6\right)$

CALL SENII SNII)

ENCOUE $(20,901,5 N E) E Z 4849$

901 FOKMAT $\left(10 \times,{ }^{\prime}+-{ }^{\prime}, F 8,6\right)$

CALL SENLISNI)

ENCOIIE $(20,902,5 N I 1) 24049$

902 FOKMAT'('24OFU/239F'U =',F8.6)

CALL SENEI(SNL)

ENCOIE (20,901, SNI ) EZ4049

CALL SENLI(SNIT)

ENACOIIE $(20,903,5 N[1) Z 4149$

903 FOFHAT ('241FU/239FU ${ }^{\prime}$, F8.6)

CALL SENEI(SNII)

ENCOIE (20,901, SNII)EZ4149

CALL SENII(SNI)

ENCOIIE (20,90., SNI ) Z5141

904 FOKMAT ('241AM/241F'U=',F8.6)

CALL SEND(SNE)

ENCOLE (20,901, SN[1)EZ5 141

CALL SENII(SNII)

ENCOEE $(20,905$, SNII $) Z 2549$

905 FOKIMAT $\left(-235 U / 239 F^{\prime} U=\prime, F 8+6\right)$

CALL SENLI(SNII)

ENCOIIE (20,901, SNL )EZ2549

CALL SENEI(SNII)

CALL SCOFY(' TIME SINCE SEF"*', SNII)

CALL STFFALI(SNII,20)

CALL SENLISNL)

ENCOIJE (20,906, SNII) FUAGE, EF'UAGE

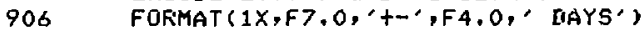

CALL SENI (SNI)

CALL SENII (F'CFLF)

C

C

OUTFUT F'LUTONIUA WEIGHT FERCENT UALLES

ENCULE (20,907, SNIH) F'23B, F'E23B 


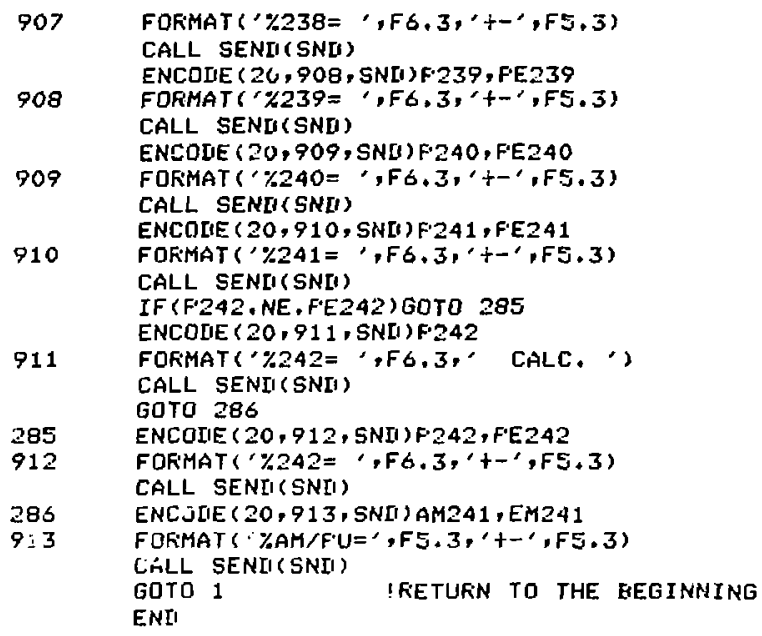




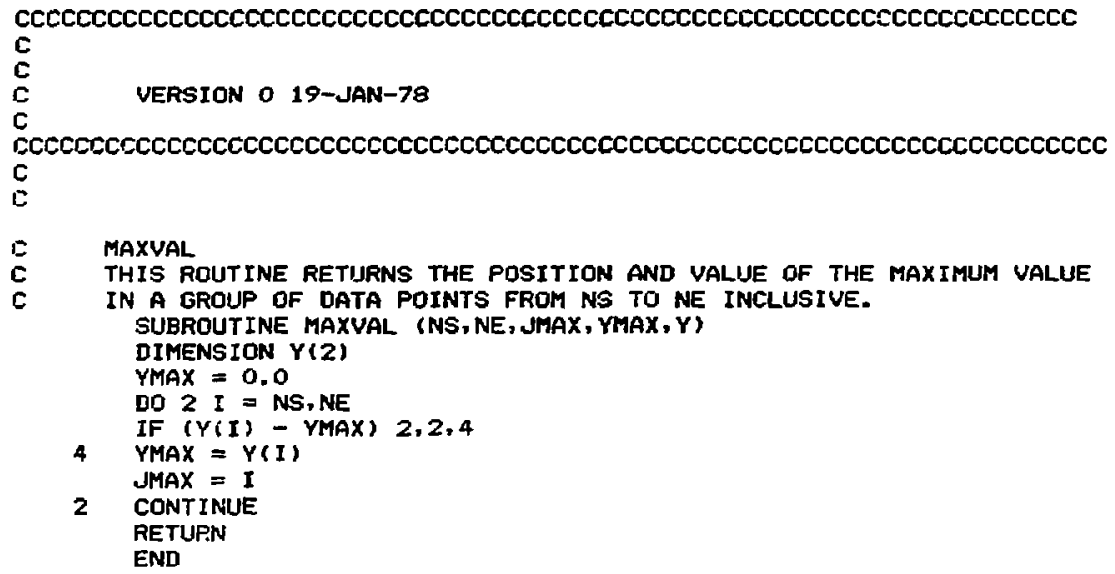


C MINVAL

C THIS ROUTINE RETURNS THE POSITION AND VALUE OF THE MIMIMUM VALUE

C IN A GROUP OF DATA POINTS FROM NS TO NE INCLUSIVE.

SUEROUTINE MINUAL (NS, NE, JMIN, YMIN, Y)

DIMENSION $Y(2)$

$Y M I N=1$ - DE 38

DO 4 I=NS, NE

2

IF $(Y(I)-Y M I N) 2,4,4$

$J M I N=I$

$Y M I N=Y(I)$

4 CONTINUE

RETURN

END 


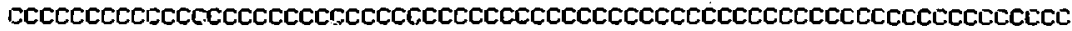

C

C VERSION 19-JAN-78

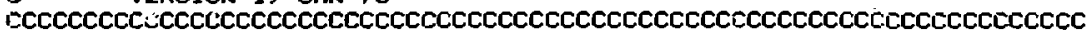

$\mathrm{C}$

E AVE

E THIS ROUTINE DETERMINES THE AVERAGE COUNT OF A GROUP OF DATA

C VALUES FROM NS TO NE INCLUSIVE. IT ALSO RETURNS THE SUM. SUBROUTINE AVE (NS, NE, SUM, AV, Y)

DIMENSION $Y(2)$

SUN $=0.0$

$\mathrm{SH}=\mathrm{NE}-\mathrm{NS}+1$

DO $2 I=$ NS, NE

2 SUM $=S U M+Y(I)$

$A V=S U M, S M$

RETURN

END 


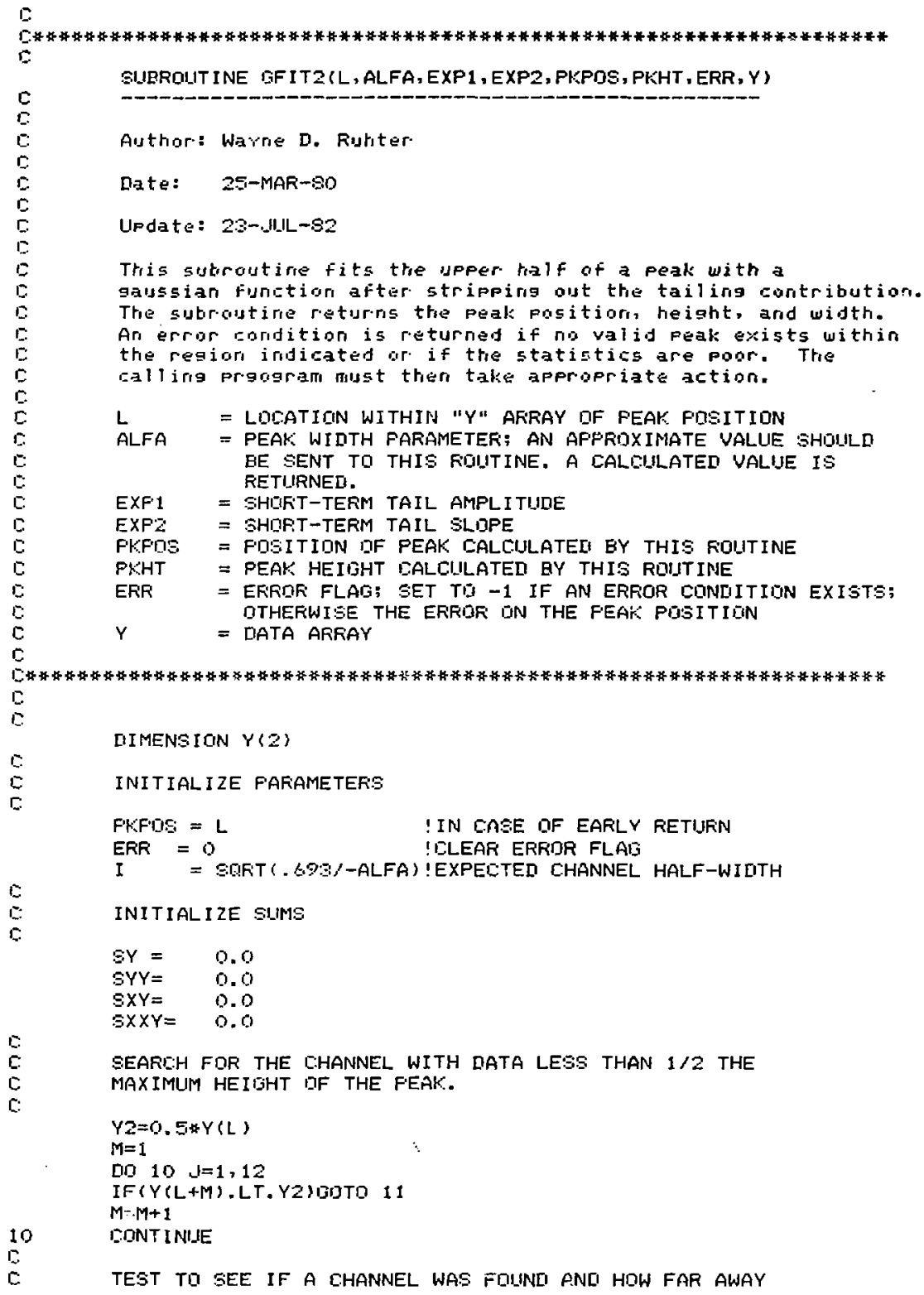

$c$

Date: 25-MAR-90

Update: $23-$ JllL -32

This subroutire fits the upper half of a peak with a gasssian function after stripping out the tailing contribution. The subroustire returns the peak positiori height, and width. An error condition is returned if no valid peak exists within the region indicated or if the statistics are poor. The rallirig program must then take appropriate action.

L = LOCATION WITHIN "Y" ARRAY DF PEAK PDSITION

ALFA = PEAK WIDTH FARAMETEF; AN AFFRIXIMATE VALUE SHOULD BE SENT TO THIS ROITINE. A CALQULATED VALUE IS RETURNED.

EXF'1 = SHIETT-TERM TAIL AMPLITUDE

EXP2 $=$ SHIRT-TERM TAIL SLDPE

FKFIS = FDSITION DF PEAK CALCIJLATEI BY THIS ROUTINE

PKHT = PEAK HEIGHT EALCILATED BY THIS ROIJTINE

EFR = ERROF FLAG; SET TO -1 IF AN ERROR CONIITION EXISTS; DTHERWISE THE ERFOK ON THE FEAK PISITIIIN

$Y \quad=$ DATA ARRAY

IIMENSION $Y(2)$

INITIALIZE FAFAMETEFS

FKFOE $=\mathrm{L}$ IIN ENEE OF EARLY RETIJFN

ERR $=0$ !LLEAR ERRIR FLAIS

I = EOFT ( . 69:-ALFA) ! EXPECTED CHANNEL HALF-WIIITH

INITIAL I ZE SLIMS
$S Y=0.0$
$S Y Y=0.0$
SXY $=0.0$
$5 \times \times Y=0.0$

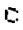

c. SEARI:H FOR THE CHANNEL WITH DATA LESS THAN $1 / 2$ THE

C. MAXIMUM HEIIJHT DF THE FEAK.

c:

$Y 2=0.5 * Y(L)$

$M=1$

DO $10 \mathrm{~J}=1,12$

IF $(Y(L+M)$. LT. Y2) BoTO it

$M-M+1$

EONT INIJE

C TEST TO SEE IF A CHANNEL WAS FOUNU ANU HOW FAR AWAY

I 


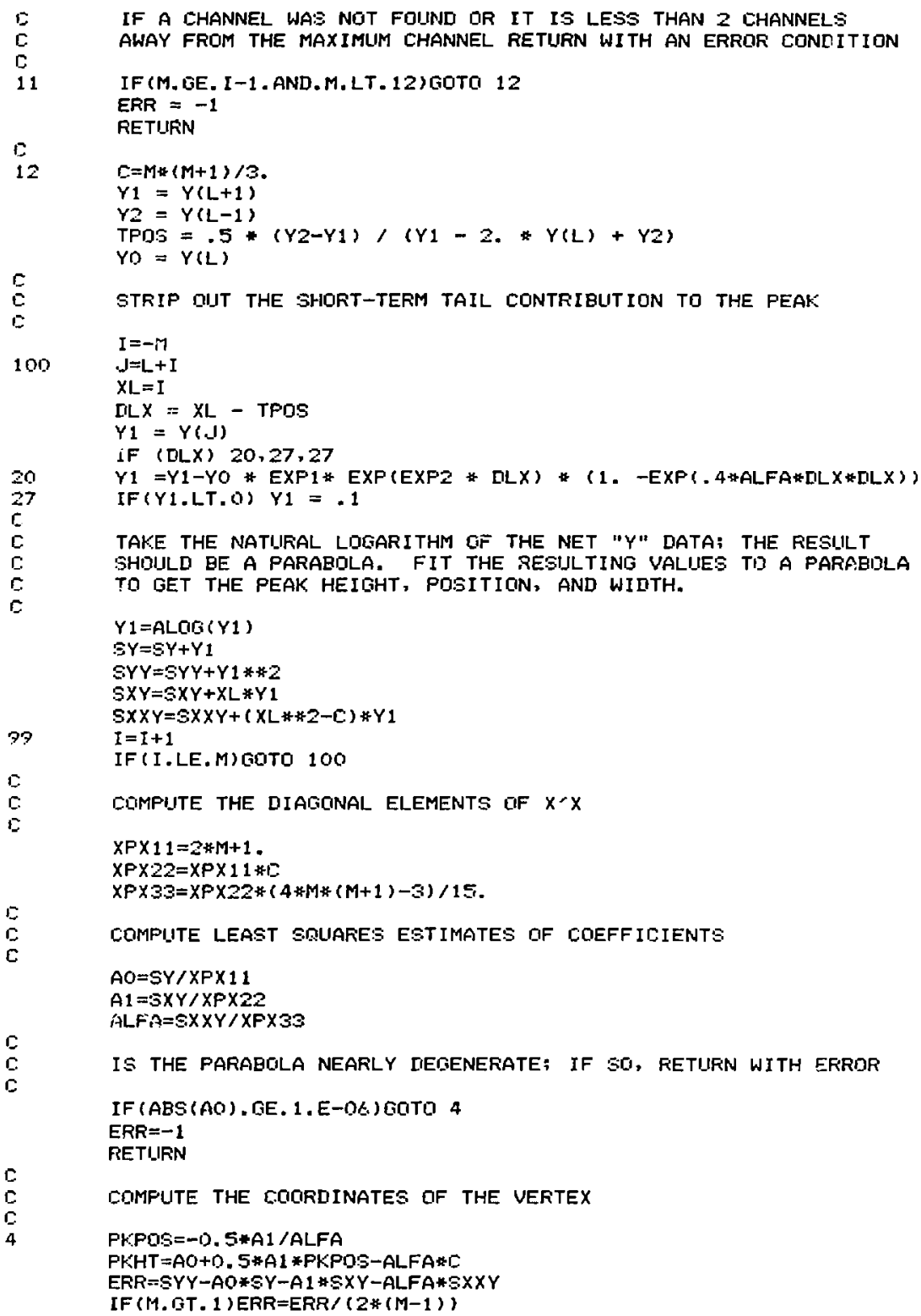


$F K F D S=F K F O S+L$

$P K H T=E X F(P K H T)$

RETLIFN

END 


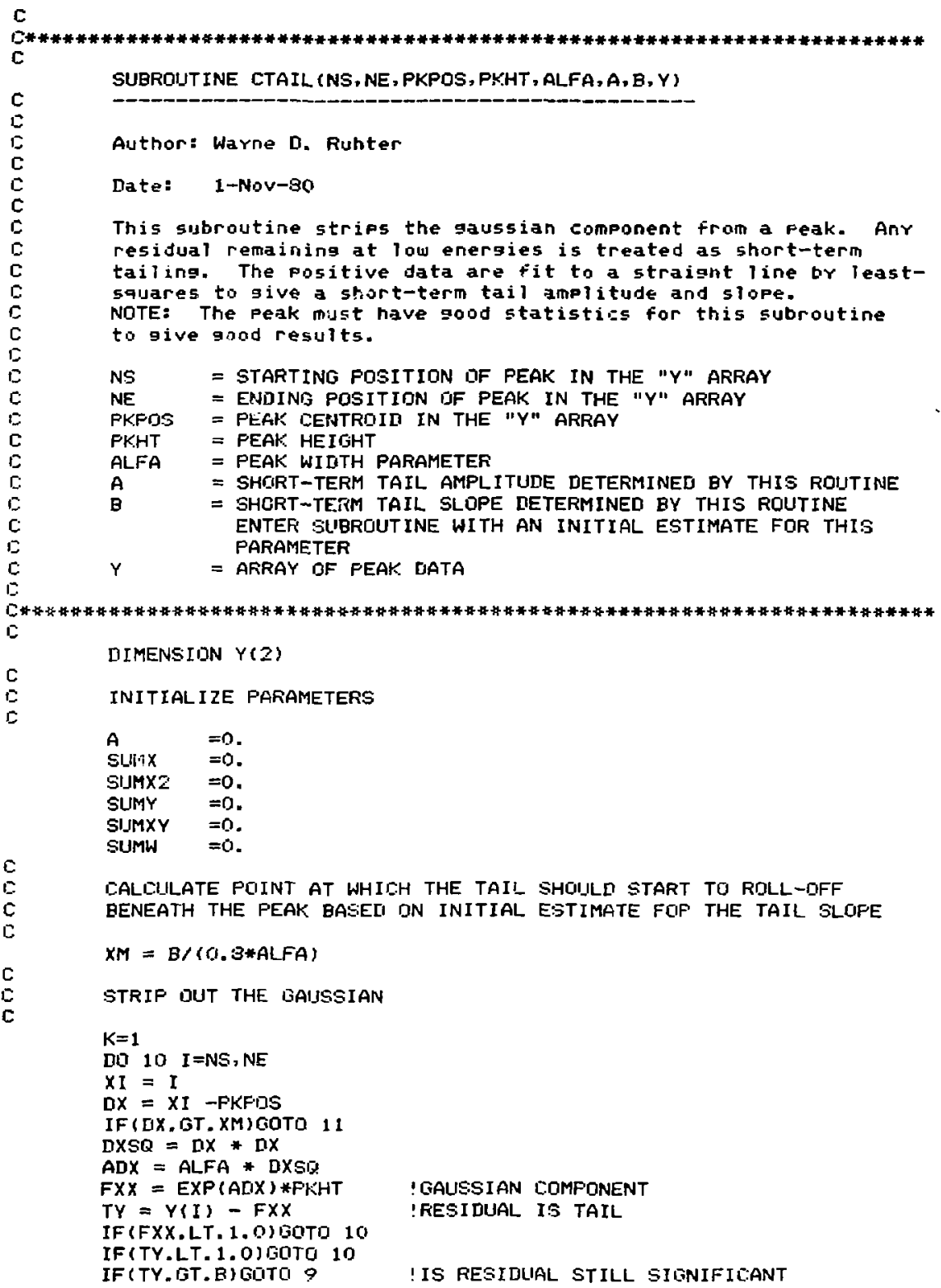


IF (K.LE. 6)GOTO 10

GOTO 11

9

$B=T Y-3 . \approx S O R T$ (TY)

PERFDRM LEAST-SQUARES FIT TO DATA WITH A STRAIGHT LINE

c

$A L Y=A L O G(T Y)$

SIMM $=$ SUM $X+D X / T Y$

$\operatorname{st} M X z=S U M X z+D X * D X / T Y$

SUMY $=$ SUMY +AL Y $/ T Y$

SUMXY $=S I J M X Y+D X * A L Y / T Y$

SUMW $=$ SUMW $+1, / T Y$

$K=K+1$

10

CONT INUE

c

IF LESS THAN 4 PDINTS ARE INVOLVED RETIRN AND USE DEFAULT VALUES

C

11

C

c

C

E

IF (K..LT . 4)RETURN

GET DETERMINANT. IF DETERMINANT IS EQUAL TO 2ERO, RETURN WITHOUT FURTHER CALCILATION.

DEL =SUMW*SIJMX 2-SUMX*BIMX

IF (DEL.EQ. O)RETURN

$A=$ (SUMX2*SUMY-SUMX*SUMXY) /DEL

$A=\operatorname{EXP}(A) / P K H T$

!SHORT-TERM TAIL AMPLITUDE

$B=$ (SUMW*SUMXY-SUMX*SUMY $) / D E L$ !SHORT-TERM TAIL SLOPE

$c$

RETURN

END 


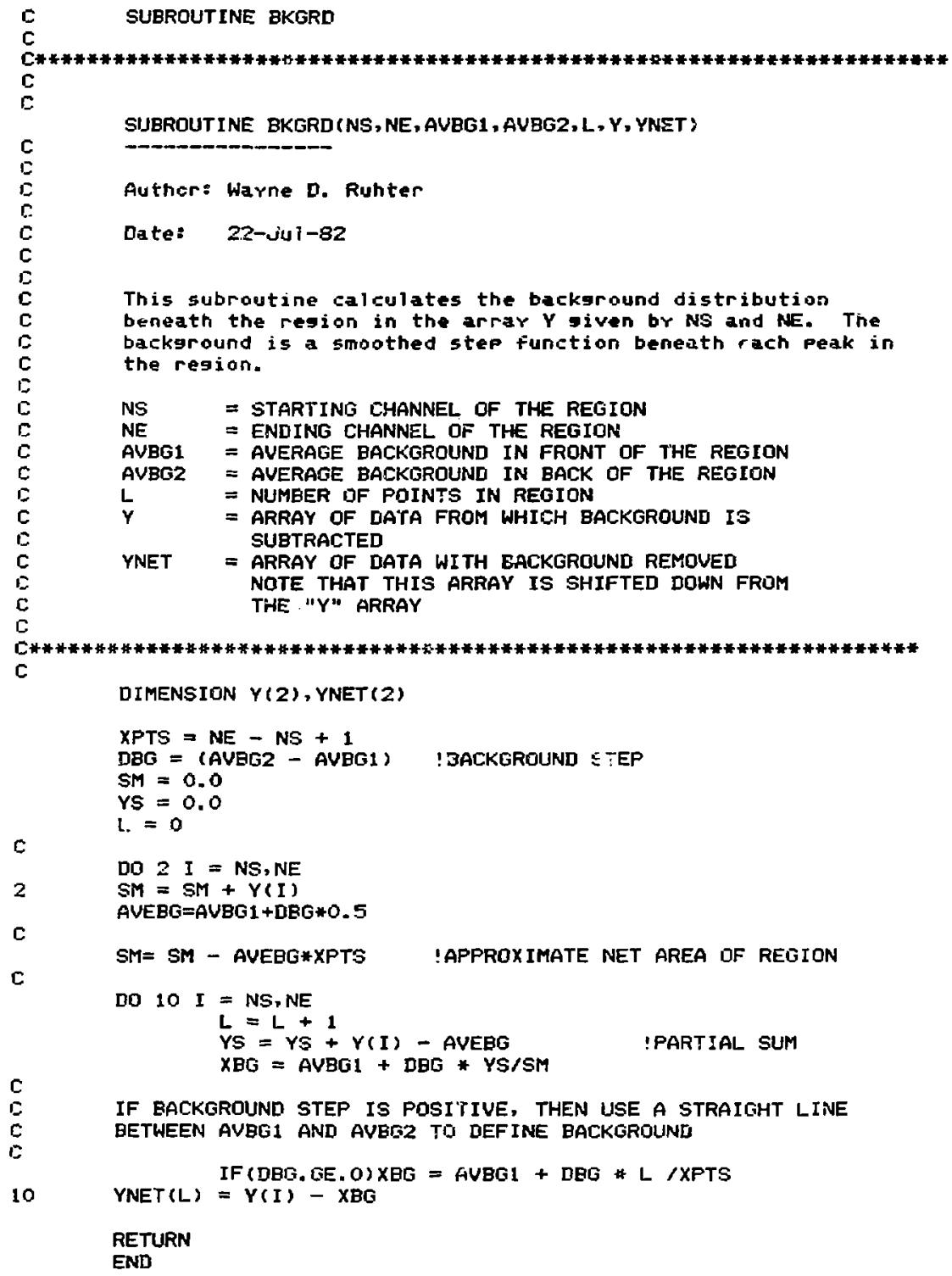


r.

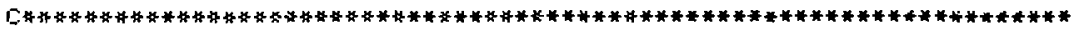
ᄃ

BIBRROUTINE STRIF (NS, NE, PKFIS, PKHT, ALFA, EXP1, EXPZ, Y)

$c$

$c$

c:

L

C.

C:

c.

$c$

c.

C.

c.

I:

5

$c$

:

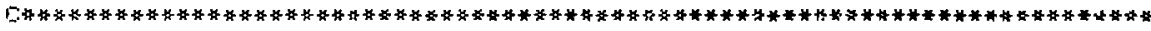
I.

8

Author: Ray Gistritirik

Date: April, 1974

This sutrustire is used to strip a peak or part of a peak from $z$ continusum.

NS: = STAFTING C.HANNEL IN $\checkmark$ ARRAY

NE $=$ ENDING CHANNEL $: N Y$ ARRAY

FKFIS = FUSITION DF PEAK

PKHT = HEIIHTT DF PEAK BEING REMIOUED

ALFA = WIDTH FARANETER DF PEAK

EXP1 = BHIIRT-TERM TAIL GMPLITIJDE DF FEAK

EXF2 = BHORT-TERM TAIL SLDPE DF FEAK

Y = ARFAY CONTAINING THE DATA ON WHILH DOMPLITATION IS FEXIDORMED

DIMENSION $Y(2)$

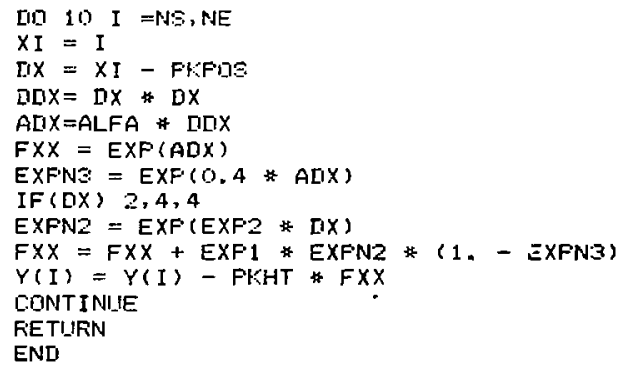




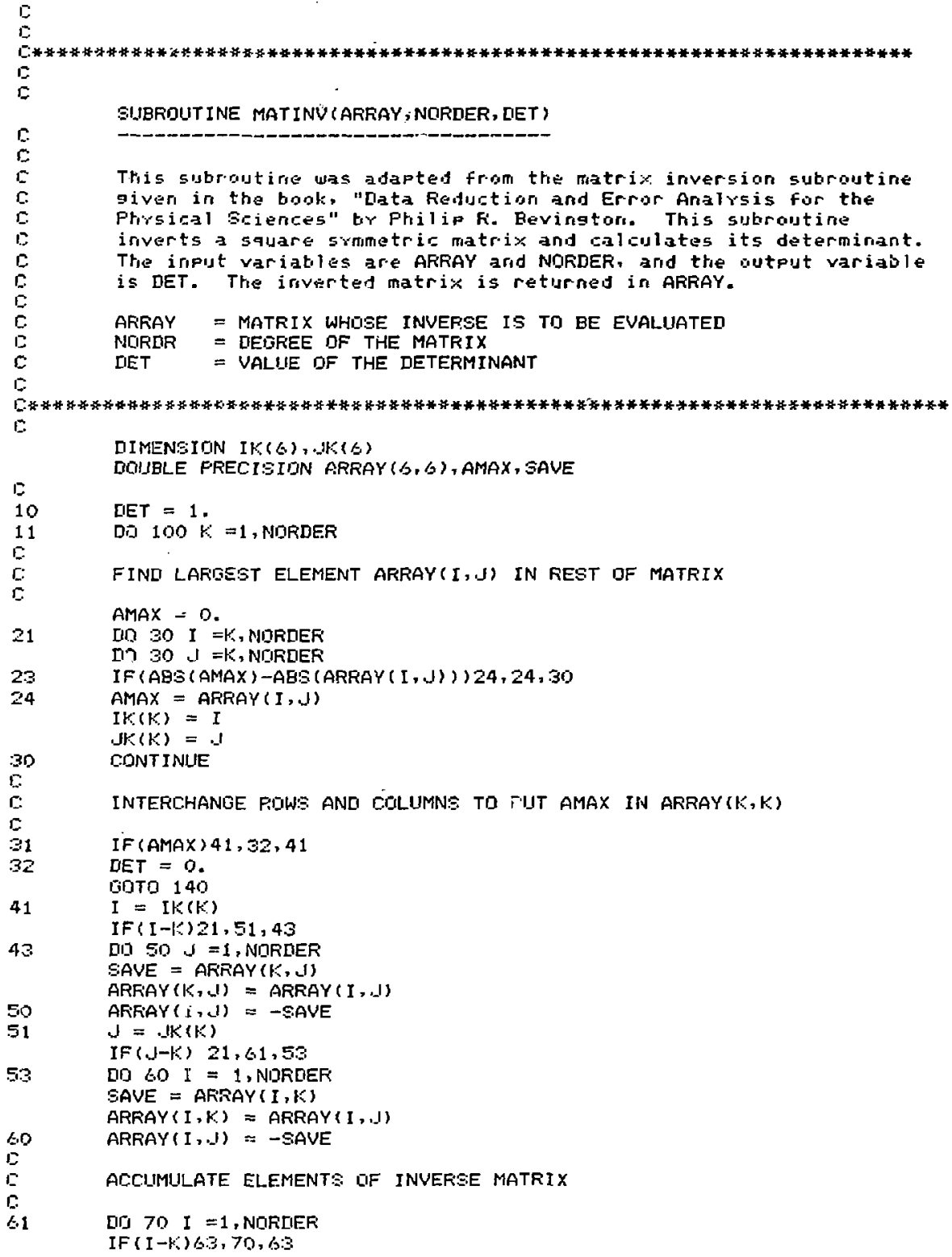

c

c.

I

c

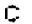

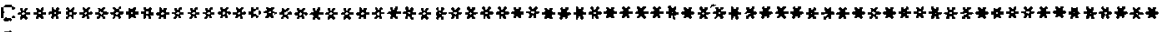
E.

This subroutire was adapted from the matrix inversion subroutine given in the book, "Data Reduction and Error Analvsis for the Phrsiazl Saiences" tr Philip F. Bevingtar. This subrautine inverts a square srmmetric matrix and calculates its determinant. The input variables are ARRAY arid NORDER, and the output variable is DET. The irsverted matrix is returned in ARRAY.

ARRAY = MATRIX WHOSE INVERSE IS TO BE EVALUATED

NORIR = DEDREE DF THE MATRIX

DET = VALUE DF THE DETERMINANT

DIMENGION IK( 6$), \ldots K(\Leftrightarrow)$

DOIIBLE FRECISION ARRAY $(6,6)$, AMAX, SAVE

I

$10 \quad$ EET $=1$.

11 DD $100 K=1$, NORDER

E.

I:

5

21 IIO $30 \mathrm{I}=K$, NORIER

Iา $30 \mathrm{~J}=K$, NCIRDER

AMAX = ARRAY $(I, J)$

$I K(K)=I$

$J K(K)=.1$

30 CONTINUE

INTERCHANGE PIOWE AND COLLUMNS TO FUT AMAX IN ARRAY $(K, K)$

31 IF (AMAX) 41, 32, 41

32 DET $=0$.

BDTD 140

$41 \quad I=I K(K)$

IF (I-K) $21,51,43$

43 DI $50 J=1$, NDRDER

SAVE = AKRAYY $(K, U)$

ARFAY $(K,, 1)=\operatorname{ARRAY}(1, \ldots 1)$

$50 \quad$ AFFiAY $(i, d)=-$ SAVE

$51 \quad J=. \mid K(K)$

IF (J-K) $21,61,53$

50 DO $60 \mathrm{I}=1$, NIREER

SAVE = ARRAY $(I, K)$

ARRAY $(I, K)=A R R A Y(I, \ldots)$

SO ARRAY $(I, .1)=$-SAVE

ACCIMULATE ELEMENTS OF INUERSE MATRIX

81 DI $70 I=1$, NORLIER

IF $(I-K) 63,70,63$

E.

c:

c

c

: 


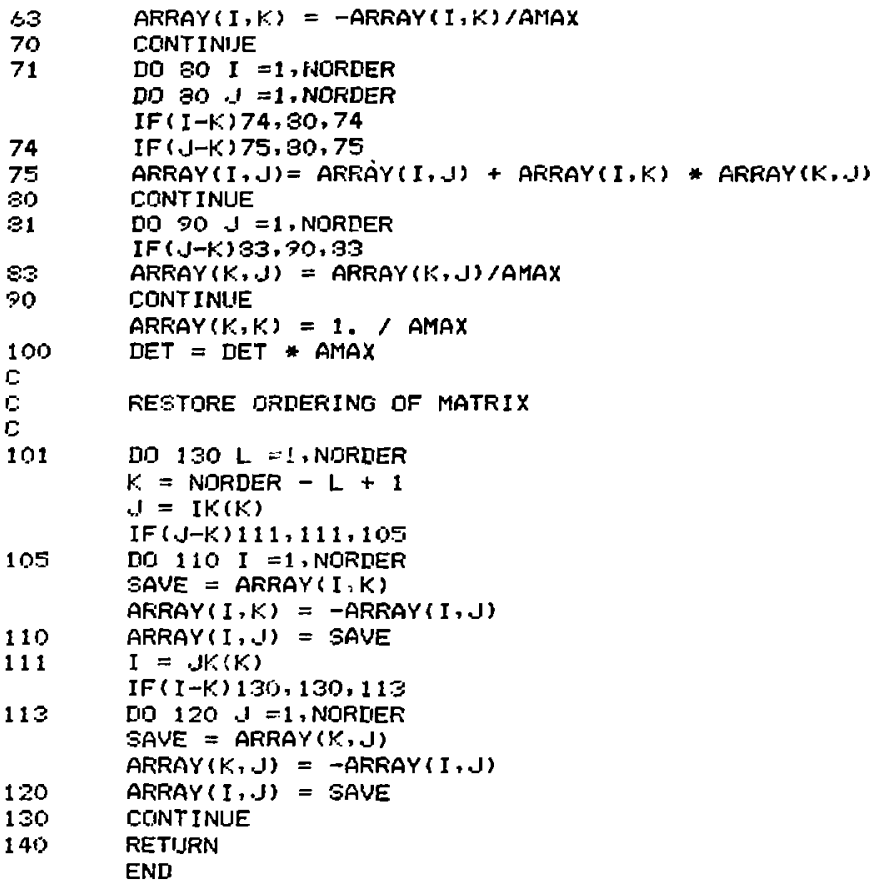




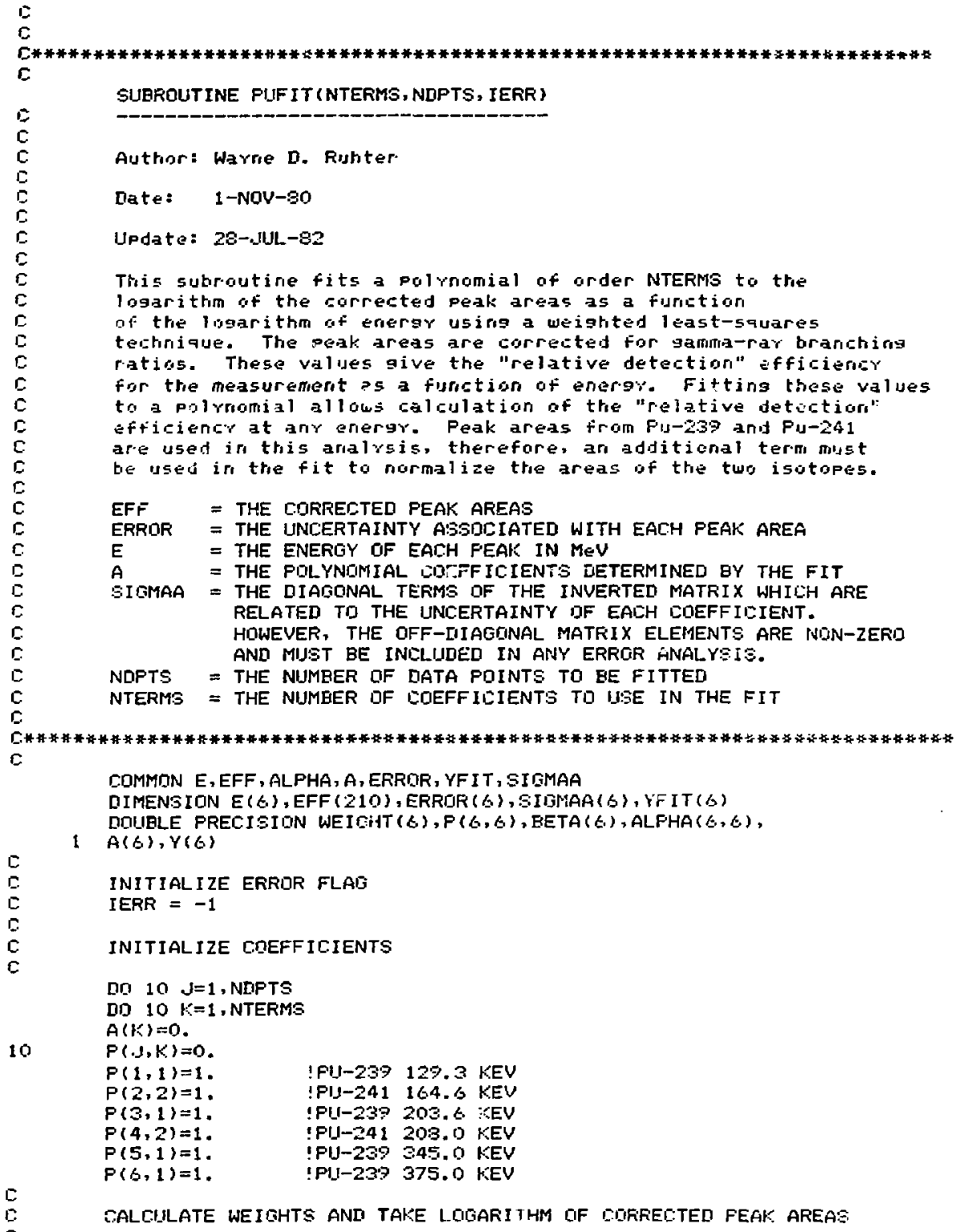


[in $40 \quad I=1$, NDF'T:

SIOMAA ( I ) =ERRDK ( I ) 100 .

WE I GHT ( I $)=1 . / B I$ I MMAA I $) \approx 2$

$\Sigma$

IF A PEAK AFEA IS ZERO, RETURN WITH ERRIOR FLAG SET

5

IF (EFF (I) . LE, O)RETURN

$Y(I)=\operatorname{ILLOG}(E F F(I))$

\&

$F(I, 3)=E(I)$

$P(I, T)=E(I) * 2$

$P(I, S)=E(I) * 3$

40

DONT INUE

C

5

5

ACCUMULATE MATRICES ALFHA AND BETA

[UD $54,1=1$, NTERMS

BETA(1) $=0$.

[ID $54 \mathrm{~K} K=1$, NTERMS

54

ALPHA $(, 1, K)=0$.

DII SS $I=1$, NDFT:

[D $S \angle .1=1$, NTERMS

$\operatorname{BETA}(, 1)=\operatorname{BETA}(, 1)+F^{\prime}(I, .1) * Y(I) * W E$ I GHT ( I )

[i1] $6 G K=1$ NTERMS

ALPHA $(, 1, K)=A L F H A(, J, K)+P(I, \ldots) * P(I, K)$ *WE IGHT $(I)$

Qs

$A L F H A(K, J)=A L F H A(, J, K)$

I

INUERT GIRUATIIFE MATRIX

1

101

5.

CALL MATINU (ALPHA, NTERMS, IET)

c

IALEULATE COEFFICIENTS AND THEIF UNCERTAINTIES

E.

111 [NO $113, i=1$, NTERMS:

DI $113 \quad K=1$, NTERMS

$113 \quad A(, 1)=A(1)+E E T A(K) * A L F H A(, 1, K)$

[0) $124 \quad j=1,5$

$124 \operatorname{EIGMAA}(.1)=\operatorname{LOGRT}(\mathrm{HLFHA}(., i, 1)\}$

IERF $=0$ ! ILEAR EFFIOR FLAIG

FETIIIRN

END 


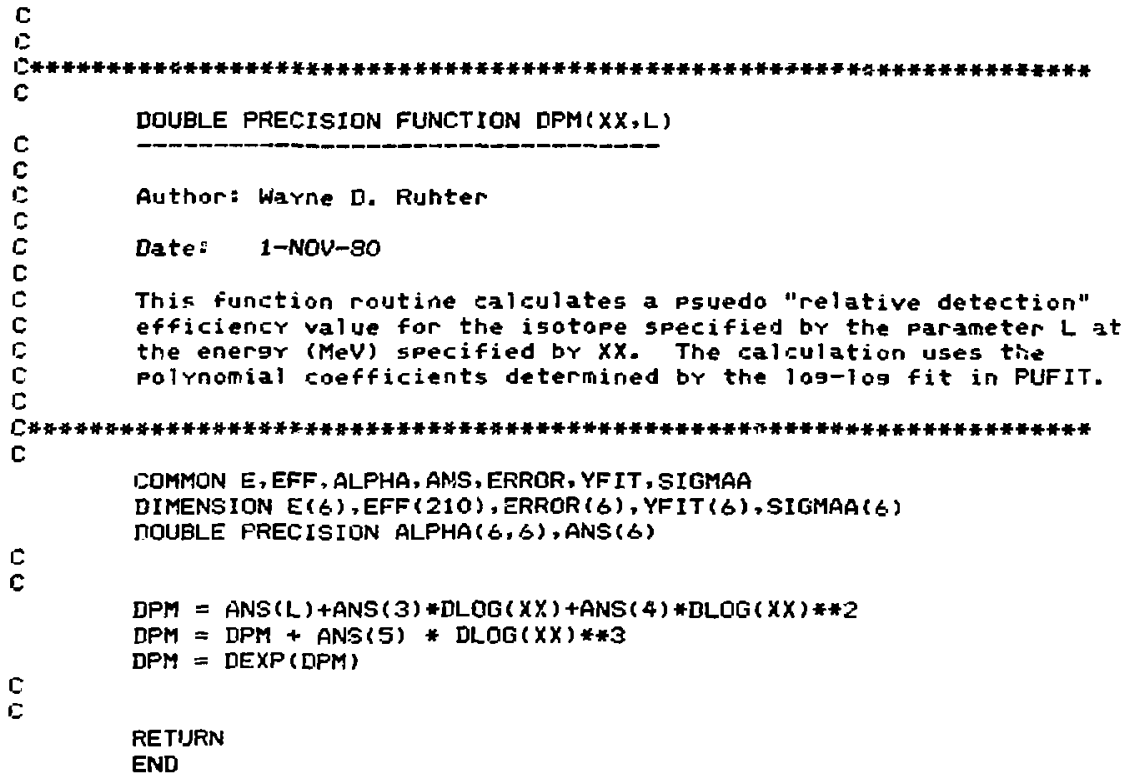

c

C

RETIJRN

END 
Author: Wayne D. Ruhter

Date: 1-Nor Bo

Update: 28-Jun-83

This subroutine receives input from the TM25 terminal and interprets it. The input mar either be a numeric entry or a function command to be sent to the Silena MCA.

A numeric entry is converted to an ASCI arrar and returned to the calling program in the arrar SND along with the number of chararters entered.

A function command entrr is interpreted in this subroutine and the appropriate action is carried out br this subroutine through the parallel interface. If the START command is entered this subroutise calls the subroutine SIREAD which reads the datz from the silena MCA brte br brte into the arrar DATA. The subroutine RECVR converts this brte arrar information into floating-point values and stores them in the arrar ARRA\%. This data arrar is returned to the calling progran throush a common statement. The number of channels read from the Silena MCA is returned br $I$ in the call statement.

$\mathrm{C}$

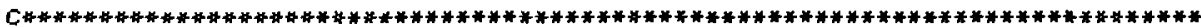
C.

LOGILAL * 1 SND (2), DATA (12300), STR (46), DCRLF (4), PCRLF (4) COMMON/DATA/ARRAY (2050)

COMMON/PIJRE/STR, DCRLF, PLRLF, ENG, ENSTCH, ENECH, NBGL , NEIG2 EOIUIVALENCE (ARRAY (1), DATA(1))

IF THIS SUBRDUTINE IS CALLED WITH I NOT EQUAL 2ERO, THIS IS A FLAÖ INUICATING THAT AN ENTRY IS TO OCOCUR SO PROCEED TO INTERCEPT IT. IF I=O, THEN WAIT FOR AN ENTRY. WHILE WAITING MONITOR THE CLIICK AND IF A MINUTE ELAPSES UPRATE THE DISPLAYEI TIME.

IST $=61$

IF ( I. NE. O)GOTO 9

CALL CLOCK (IDAY, IMO, IHR, IST) $\mathbf{I}=\mathbf{0}$
I INITIALIZE TO MONITQR DLOCK

!GET READY TO RECEIVE

!GET TIME TO BEGIN MIJNITISR

! INITIALIZE EYTE COUUNTER

IF ( IPEEK ("176500) . EQ. "200 s00TO CALL CLOCK (IDAY, IMO, IHR, IMIN)

11 ! TM25 HAS CHARACTER?

IF (IMIN.EQ. 0.AND. IST.EQ.53) IST =-1 !RETIJRN UN THE HOIJR

IF (IMIN. GT. IST)RETURN BOTO 10
ISND= IFEEK $(176.502)$

IF(ISND. ER. "215)GOTO 19

$\operatorname{SND}(I+1)=I$ SND -1200

IF (SND $(I+1)$. EG." 12$)$ GOTO 19

$I=I+1$

DOTQ 10

IF (I.ES. 1) G0TC 200
! IF MINIJTE ELAF:SES RETURN TO

!DISPLAY; UTHERWISE KEEP LOUKINIS

!YES, GET CHARACTER

! DARRIAGE RETURN -END OF NUMEFIC INFUT

ISTRIF EXTFIA BITS

IEXTFIA CHARACTER GO EACK

!CIIJNT BYTE

!LOGK FGR MORE LHAFALTER:S

!NO NIMERIC ENTRY; LOILK FOS COMMAND 


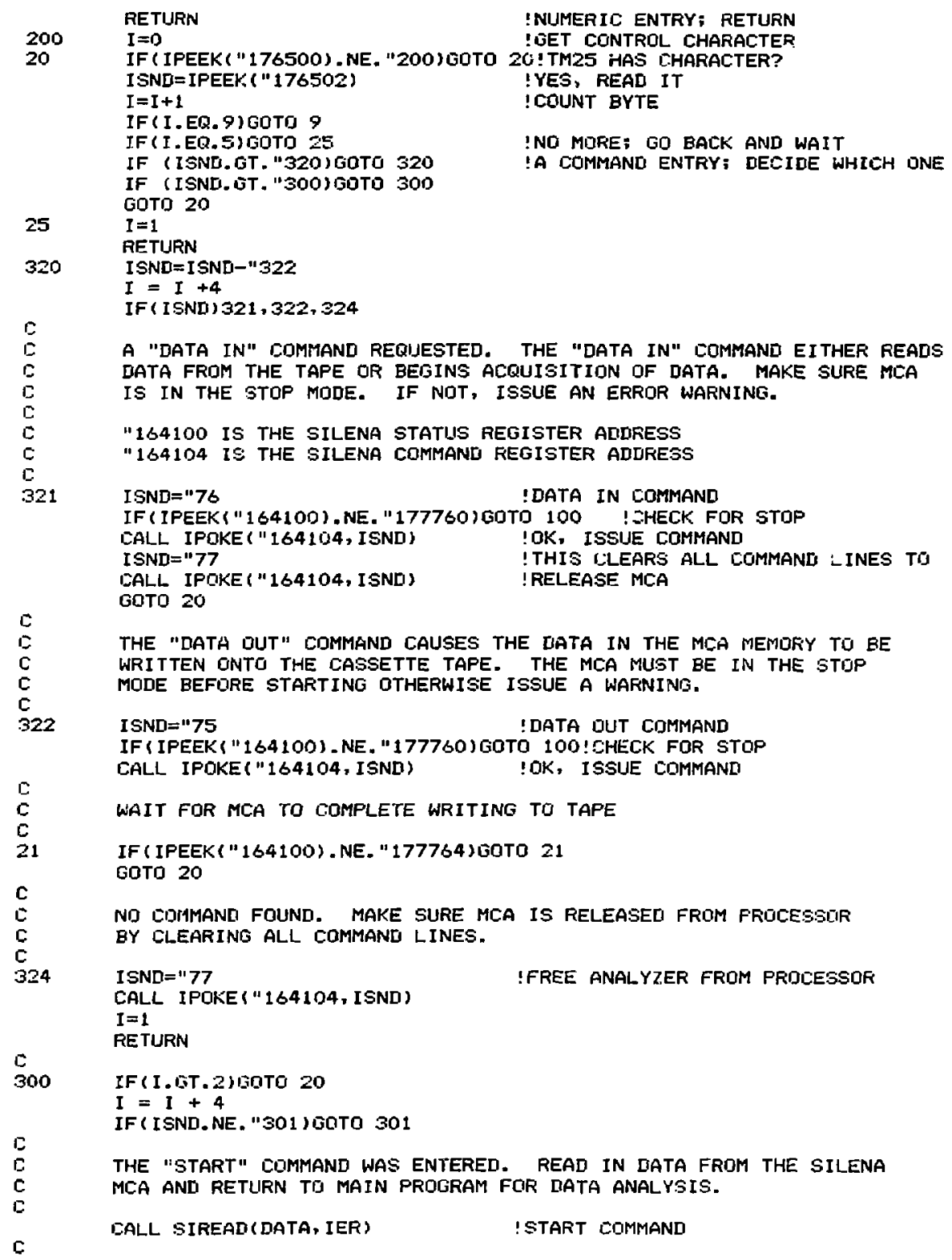




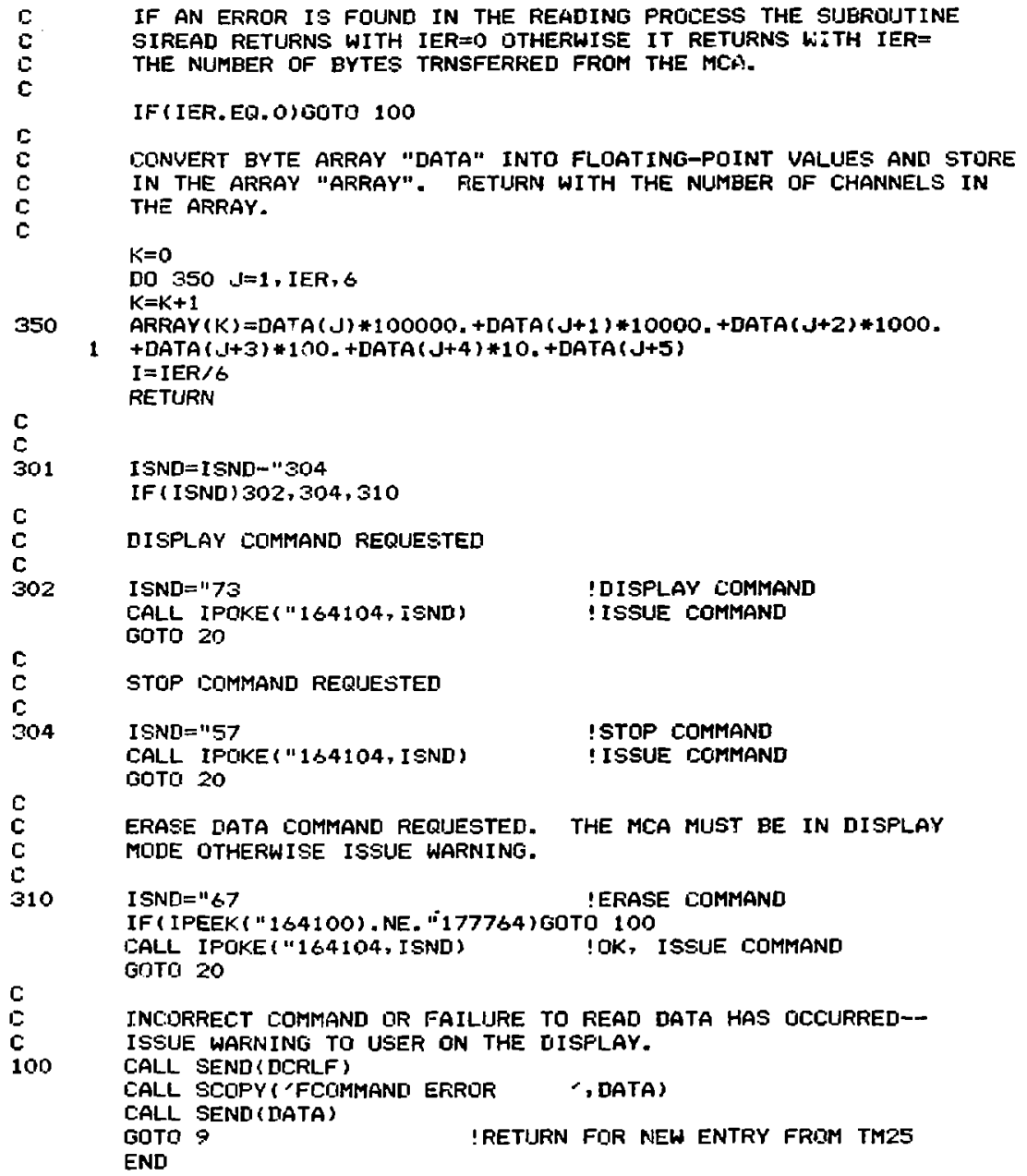




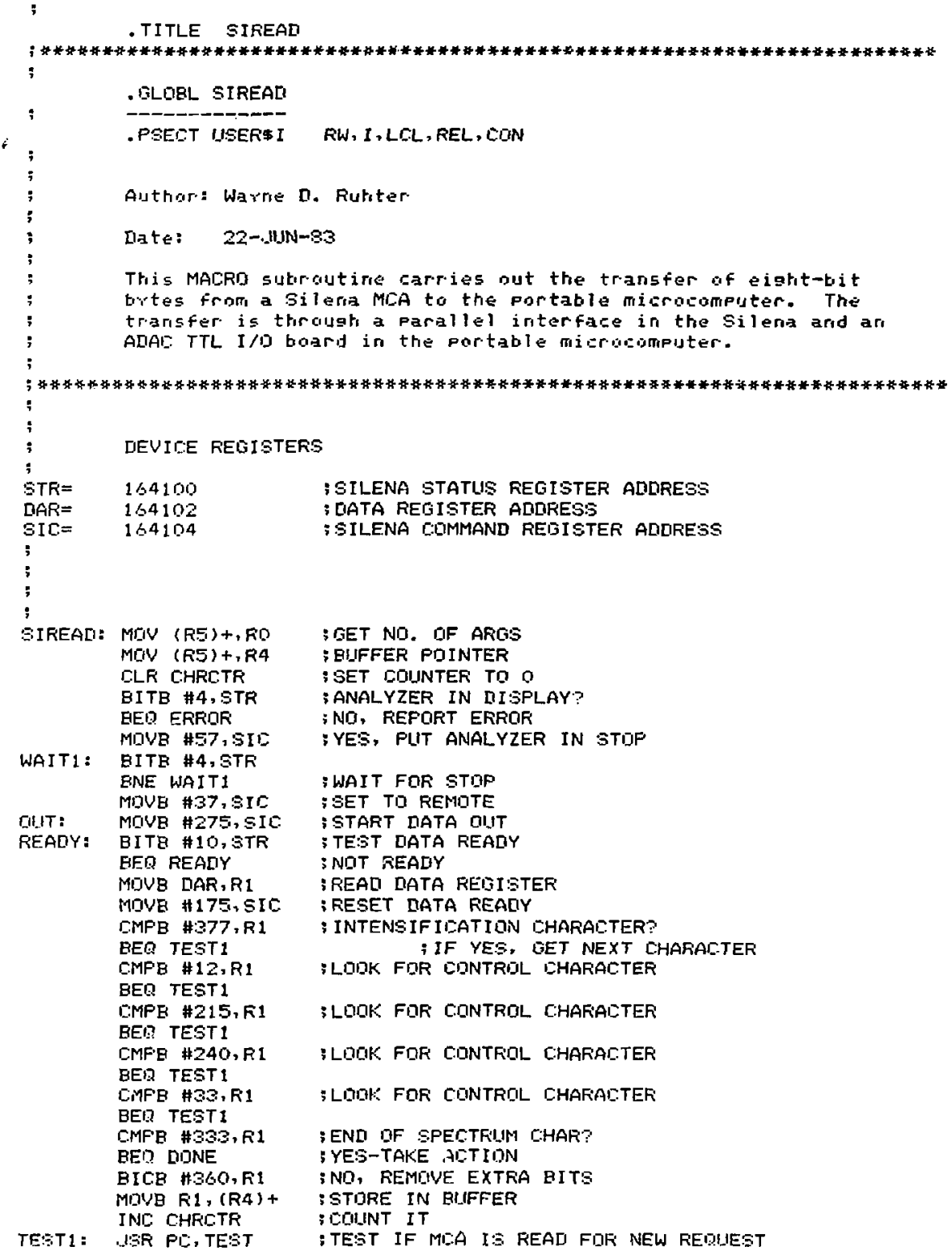


ER OLIT

IUDNE: MIUE \#SO, R.S ; REAB REMAINING CHARACTERS

JSR PE.TEST ;TEST IF MEA IS READ FOF NEW REQUEST

IIIT 1: MOVE \#275,SIC ; THERE ARE 40 TFAILING CHARALTERS AT THE END

RDY2: BITB H10,STR

BEQ RDY?

MOVB A175,SII

-ISR FC, TEST

; TEST IF MCA IS REAT FOR NEW REQUEST

SOB R. DINT 1

MOVB \#275, SIC

MOVB \#77, SIL

ERIROR: MIOU CHRCTR, C(RS): SEND BACK THE \# OF CHARACTERS

RTS FC

TEST WHETHER MCA DATA REAIIY STATU: I $\Xi$ CLEAREI

;

;

TEST: QITR \#1C,STR

RNE TEST

RTS PE:

THIS PBELT DEFINITIIN FDRLES THE VAFIARLE "CHRCTR" INTI

THE RAM MEMARY. "CHRITR" DIDNTS THE NLMEER DF VALID DHARALTER:

TFANSMITTEI FRIMM THE SILENA MCA.

;

- PEECT IISER\$D

DHRETR: "WIRD

0.

RW, D, LCL , REL , GDN

. END 


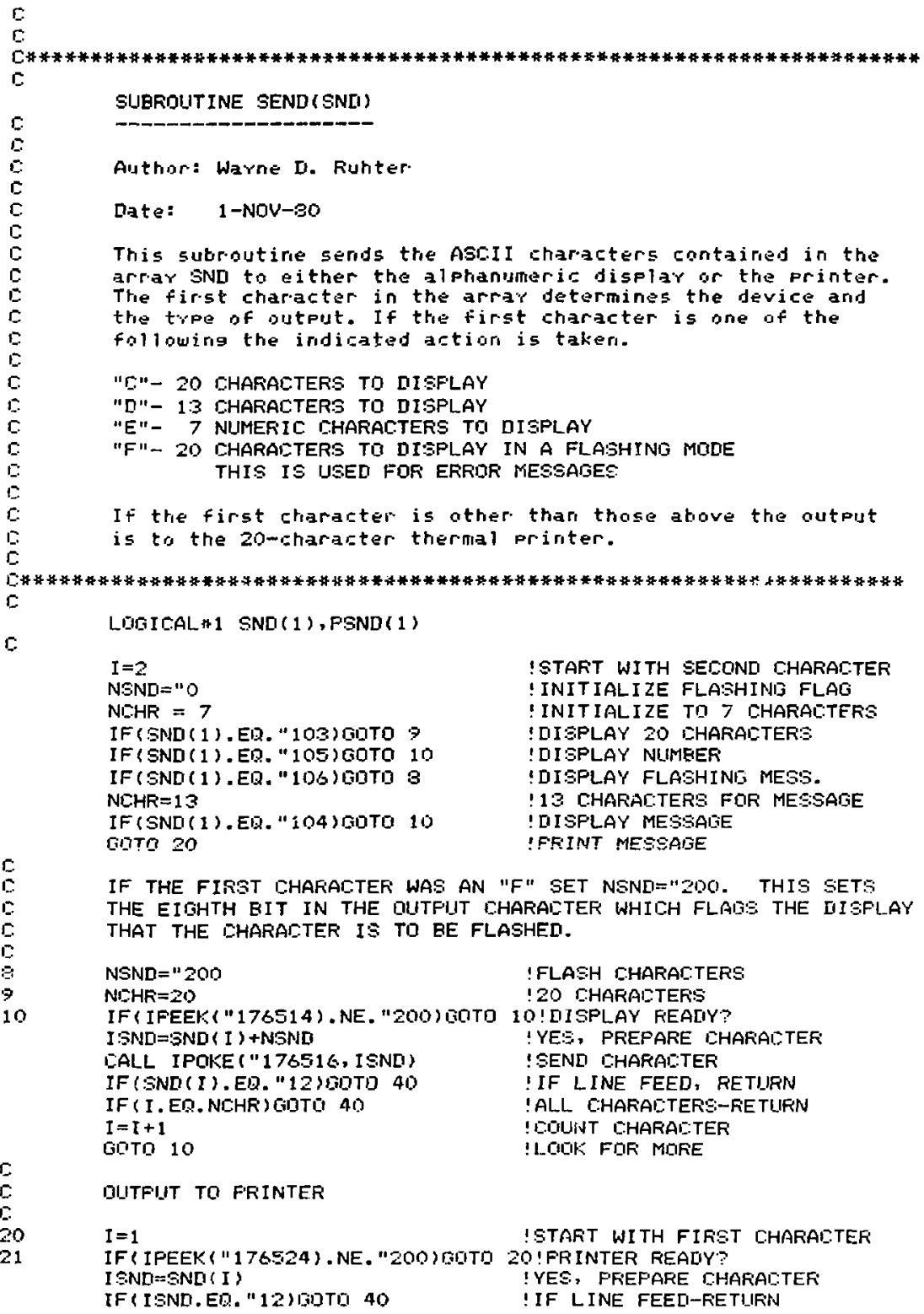




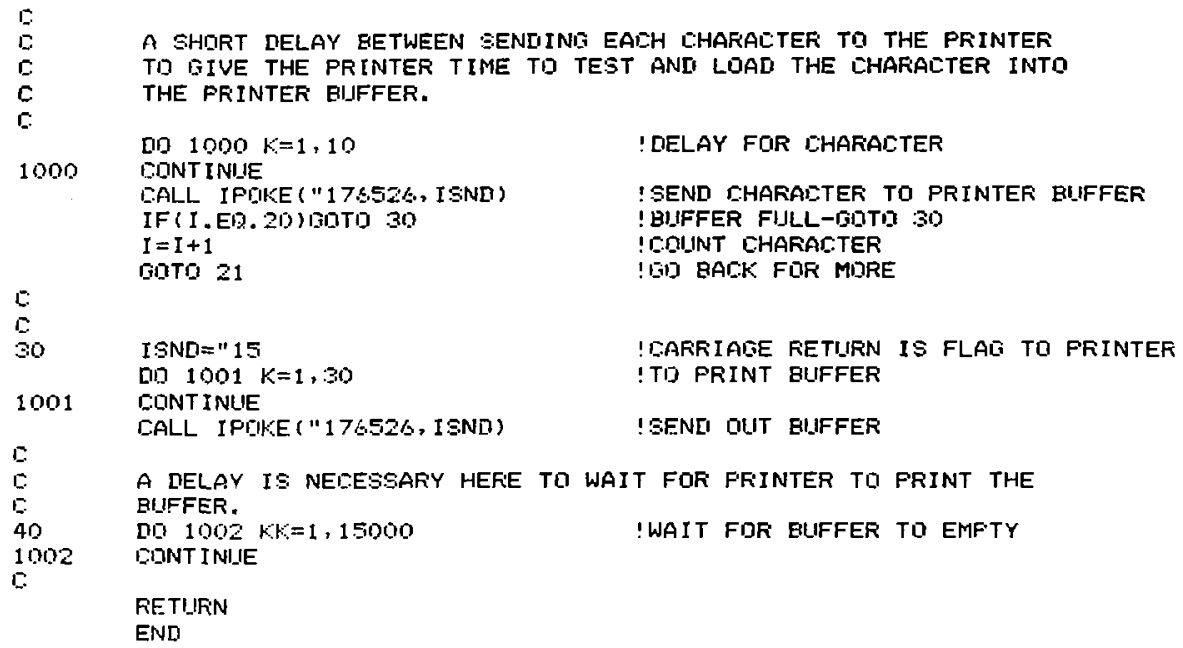

RETIURN

END

!WAIT FDR EUFFER TO EMFTY 


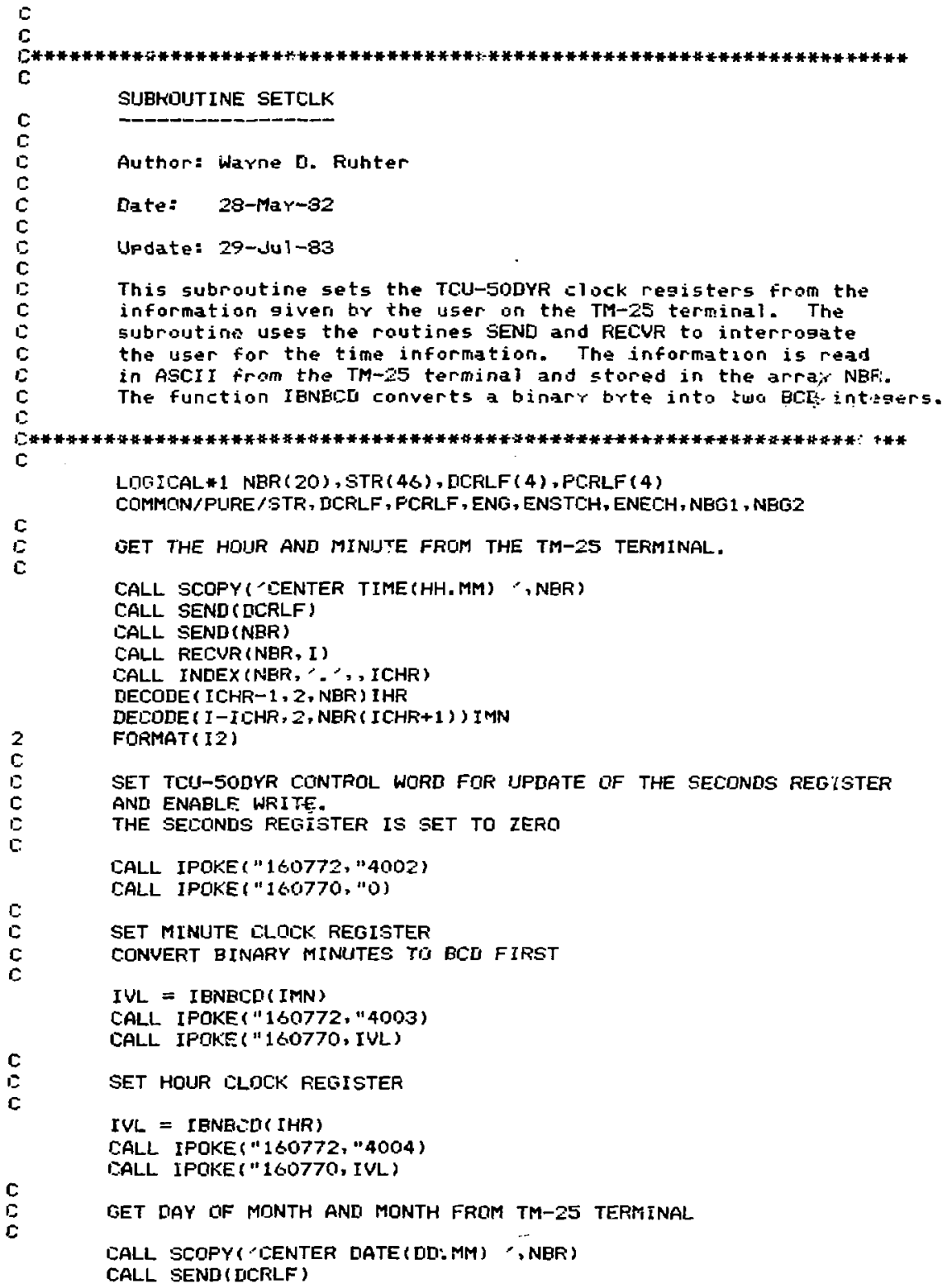

C. 
CALL SEND(NER)

CALL RECUR (NBR, I)

CALL INDEX (NBR,".', ISHR)

DECODE (ICHR-1, 2, NBR ) IDAY

c

DECODE (I-ICHR, 2, NER (ICHR+1)) IHO

C

$c$

SET TCU-5ODYR CONTROL WORD FOR DAY OF MONTH UFDATE

CALL IFOKE("160772,"4006)

c

E

C

SET DAY DF MONTH CLOCK REGISTER

$I V L=I B N B C D(I D A Y)$

CALL IPOKE("160770, IVL)

C

c

SET MONTH CLDCK REGISTER

IVL = IBNBCDI IMO)

CALL IPOKE("1\$0772,"4007)

CALL IPOKE ("160770, IVL)

c

$c$

$\mathrm{C}$

C

GET YEAR FROM TM-25 TERMINAL AND STORE IN TCU-5ODYR CMOS

RAM. THE YEAR IS UPDATED BY SOFTWARE (SEE THE SUBRUUTINE YEAR;

RATHER THAN HARDWARE. THIS NECESSITATES THAT THE CURRENT

MONTH ALSG BE STORED IN TAM.

CALL SCOPY (CENTER YEAR (YY), "NBR)

CALL SEND (DCFLF)

CALL SEND(NBR)

CALL RECUR (NBR, I)

DECOODE ( I , 2 , NER ) I IR

CALL SEND(NCRLF)

PIJT YEAR IN CMOS RAM

CALL IPOKÉ("160772,"7777)

!SELECT ClOCK RAM ADDFESS

$I V L=I$ BNBCD (IYR)

!AND ENABLE WRITE

CALL IFOKE("160770, IVL)

SET CIJRRENT MONTH ALSO

CALL I: . TKE ("160772,"7776)

$I V L=I B N B C D(I M O)$

CALL IFDKE("160770, IVL)

C

RETIJRN

ENII

c

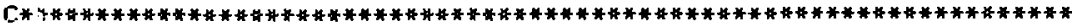

C

E

FIINCTION TI CONUERT A BINARY VALUE TO TWI BCD INTEGERS CUNTAINEI IN DINE BYTE.

I

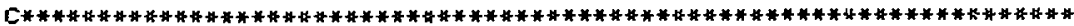

$\mathrm{C}$

C

FIJNCTION IBNBCD(IVL)

C

IONE $=\operatorname{MOD}(I V L, 10)$

ITEN $=($ IVL-IOINE $) / 10$ 


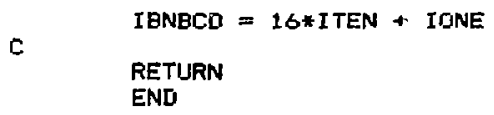

64 
aNG

NURIJy

(7^I) NGaJaI $=$ DWI $\left(0 \angle \angle O 9 \tau_{n}\right) \times 3 \exists \exists d I=7 \cap I$ $\left(\angle, " Z \angle \angle O Q T_{11}\right) \exists>10 d I 77 \forall 3$

HLNOW 139

( ᄀกI ) NaAJaI $=\wedge \forall Q I$

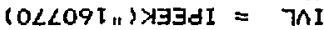

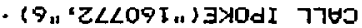

AצษNIE OL aOE LABNNDJi

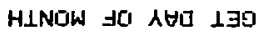

$(7 \cap I)$ NEgJ日 $=\mathrm{HHI}$ $\left(0 \angle \angle 0 \tau_{n}\right) \times \exists \exists d I=7 \cap I$

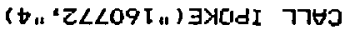

$\exists r$ เาษ 8 ชัIOH $1 \exists 9$

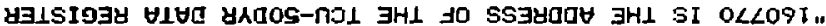

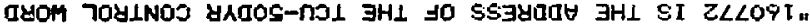

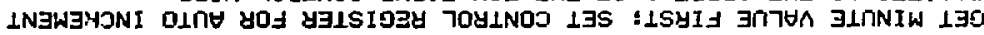
$\left(0 \angle \angle 09 I_{1}\right) \times \exists \exists d I=$ TNI

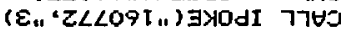

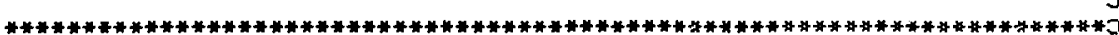

$$
\begin{aligned}
& \exists \perp \cap N I N \pm 0 \text { ヨnר } \forall \text { Y }
\end{aligned}
$$

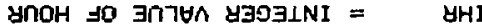

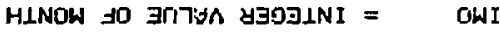

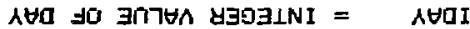

-pJeaq y

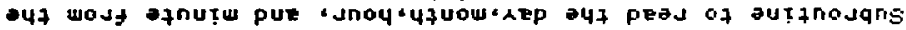

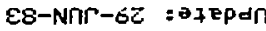

$$
\begin{aligned}
& \text { 2B6t-גEW-82 : 27Eg }
\end{aligned}
$$

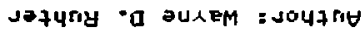


C

FUNCTION TO CONVERT 2 BCD DIGITS CONTAINED IN ONE BYTE

C TO A BINARY NUMBER.

conte

C

c

$c$

FUNCTION IBCDBN(IVAL)

i.

ITEN $=$ (IVAL.AND. "360)

ITEN ITEN/16

IONE = (IJAL. AND. "17)

c

IBCDBN = IONE + 10 * ITEN

\section{RETURN}

END 
c

is

c

SUBROUT INE YEAR (IYR)

c

$c$

$c$

c

c

c

C

I

C

C

$c$

C

C

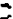

C

I

Author: Warne D. Ruhter

Date: 28-Mar-82

Update: 29-(1!)-83

This subroutine reads the year from the TCU-5ODYR CMOS RAM. This subroutine is responsible for maintaining the psuedo year counter in the TCU-50DYR's batterr supported CMOS RAM. It is necessary to run this routine at least once aef rear to ensure that rear counter is bumped appropriately. Each time this routine is used the current month is stored in the CMDS RAM. C

I.

GET YEAR FROM CMOS RAM

"160772 IS THE ADDRESS OF THE TCU-SODYR CONTROL WORD

"160770 IS THE ADDRESS OF THE TCU-SDDYR DATA REGISTER

" 3777 SELECTS THE YEAF FROM THE CMOS RAM

THE FUNCTION IBCDEN CONUERTS A BCD NUMBER TO BINARY

(Ses listing for CLOCK subroitine.)

CALL IPOKE("1\$0772,"3777)

IVL $=$ IPEEK $" 160770$ )

IYR = IBCDBN (I.VL $)$

c

BET LAST MONTH FROM CMOS RAM

CALL IPOKE("160772,"3770)

LMO = IPEEK ("160770)

c

c

C

BET DURRENT MONTH FROM TCIJ-SODYR CLOCK

CALL IPOKE("160772,"7)

IMD = IPEEK\{"150770)

L

c

C

STORE CURRENT MONTH IN CMOS RAM

CALL IPOKE ("160772,"7776)

CALL IPOKE("160770, IM(J)

E

COMPARE :-AST MONTH AGAINST CURRENT MONTH

IF CURRENT MONTH IS LESS THAN LAST MONTH, INCREMENT

THE YEAR AND STORE THE RESULT IN THE CMOS RAM.

IF ( IMO. GE. LMO) RETURN

INCREMENT YEAR

$I Y R=I Y R+1$ 
E

C

E

c

C

I

"7777 LOADED INTO THE CONTROL WORD ENABLES WRITING INTO THE YEAR ADDRESS OF THE CMOS RAM.

CALL IPOKE("160772,"7777)

THE FUNCTION IENBCD CONVERTS A BINARY NUMBER TO A BCD NUMBER

IVL $=$ IENBCD $($ IYR $)$

CALL IPOKE("160770, IVL)

RETURN

ENI 
MACFO DODE TO DRDER PSECTS WITH FURE CODE FIRST

IMFIJRE COODE ANL DATA LAST

FURE DODE AND DATA SECTIONS FOLLIW

. PSECT DTS\$I

.PEECT DTSEP

-PEECT SYS\$I

- PISECT JGER\$I

- FISECT \$CONE

-P:SECT OTS\$O

- F:SECT SYS\$D

-P:3ECT \$DATAP

-P:SECT PIIRE

. PSECT RT:\$D

FW, I, LCL, REL, , CON

RW, $D$, GBL, REL, QUR

;

;

IMPUIRE CODE AND IIATA PSECTS FOLLOW

. PSETT DITS\$S

- PSECT SYS\$E

- FSECT sDATA

. PSELT JaERTD

- PSELT . \$\$\$\$.

. FSECT LATA

- PSELT \$STACK

- PSEET \$ETKGT
$R W, D, L C L, R E L, G O N$

RW, D, LCL, REL, CON

RW, D, LCL, REL, BON

$R W,[1, L L L, R E L, C O N$

RW, $D, G E L, R E L$, QVR

RW, D, GEL, REL, OUR

RW, $D, L C L, R E L, C O N$

$\mathrm{RW}, \mathrm{D}, \mathrm{LCL}, \mathrm{REL}, \mathrm{EON}$

;

- EML 


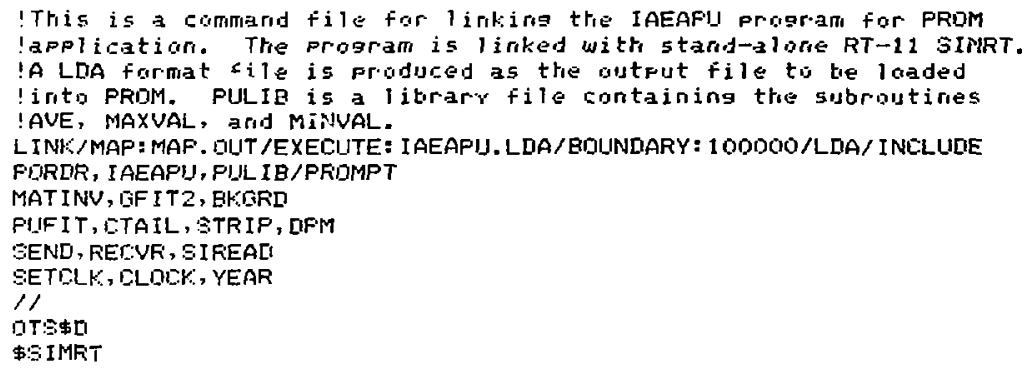




\begin{tabular}{|c|c|c|c|c|c|c|c|c|}
\hline $\begin{array}{l}F T-11 \text { L } \\
\text { XIAEAP.L }\end{array}$ & $\begin{array}{l}\text { INK } \\
\text {-DA }\end{array}$ & $\begin{array}{l}O 4 A \\
T i t 1=:\end{array}$ & $\begin{array}{l}\text { Load Ma } \\
\text {.MAIN. }\end{array}$ & Ident: & FIRUOZ & & & \\
\hline Sertion & Adstr & Size & Olotral & Valde & G1 obal & Value & Slobal & Value \\
\hline - ABS. & 000000 & 001000 & $(R W, I$, & $G \mathrm{BL}, \mathrm{ABS}$ & (VF) & & & \\
\hline & & & \$ISRSW & 010000 & \$FFZAI & 000000 & $\$ N L C H N$ & 000006 \\
\hline & & & DHR[IWR & 000006 & \$SYSV\$ & 000011 & \$WASI I & 000152 \\
\hline & & & \$LFEECL & 000210 & \$TRACE & 004737 & & \\
\hline DT:SI & 001000 & 026642 & (RW, I, & $L C L, R E L$ & SDN & & & \\
\hline & & & \$\$1TSI & 001000 & $A D F \$ I M$ & 001000 & $A D F \$ F M$ & 001000 \\
\hline & & & $A D F \$ M M$ & 001012 & $A D F \$: B M$ & 001022 & SUF\$IM & 001042 \\
\hline & & & $\begin{array}{l}\text { :UJF } \$ S M \\
\text { AUF } \$ \text { IF }\end{array}$ & $\begin{array}{l}001050 \\
001134\end{array}$ & $\begin{array}{l}S \amalg F \$ P M \\
A D F \$ F P\end{array}$ & $\begin{array}{l}001100 \\
001142\end{array}$ & $\begin{array}{l}\text { SUF\$MM } \\
\text { ADF\$MP }\end{array}$ & $\begin{array}{l}001104 \\
001146\end{array}$ \\
\hline & & & ADF\$SF & 001156 & SUF\$IP & 001176 & SIIF\$SF & 001204 \\
\hline & & & SUF $\$ F P$ & 001234 & SIJIF & 001240 & ALOIB 10 & 001286 \\
\hline & & & ALDS & 001272 & \$EUTFE & 001646 & $\$ C: U T F I$ & OOLSAt \\
\hline & & & CEF\$ & 001000 & r:DF $\$$ & 001600 & $\$ R L$ & 001660 \\
\hline & & & $\$ F: D$ & $001 \leqslant 60$ & $\$ E \cup T F B$ & 001678 & \$DUTF I & 001676 \\
\hline & & & \$EVTEB & 001712 & \$EVTCI & 001712 & \$LVT[B & 001712 \\
\hline & & & \$EVTDI & 001712 & CILD & 001724 & CI I1\$ & 001724 \\
\hline & & & CLC. & 0121724 & CLחE & 001724 & का I & 001724 \\
\hline & & & CIF & 0011734 & ELF\$ & 001734 & \$RI & 001734 \\
\hline & & & EIL & 002042 & CLI\$ & 002046 & \$CVTIF & 002050 \\
\hline & & & \$CVT IC & $0020 \leqslant 4$ & \$CVTIL & $0020<4$ & CE:I\$ & 002076 \\
\hline & & & E:II & 002076 & $\$ 11$ & 002076 & FI D & 002076 \\
\hline & & & {$[: F I \neq$} & 002112 & \$IR & 002112 & कCVTLIF & 002176 \\
\hline & & & C:FDS & 002210 & F[IR & 002210 & RLI I & 002242 \\
\hline & & & racoso & $00 e_{2} \mathrm{~s}$ & FCoDs & 003284 & EDO\$ & $00: 270$ \\
\hline & & & {$[161 \%$} & 003276 & SULI\$F & 004220 & SUD\$MS & 001424 \\
\hline & & & $A D[1 \$ \mathrm{PS}$ & 004244 & ADD\$MS & 004250 & A[III\$IS & 004270 \\
\hline & & & SIII\$ IS & $004: 302$ & \$ADDD & 004314 & \$:IJBD & 004330 \\
\hline & & & SUL1\$SS & 004342 & \$SBD & 004242 & ALID\$SS & 004344 \\
\hline & & & \$ALID & 014346 & DIn\$P: & 005426 & DI D\$MS & 005432 \\
\hline & & & DIDSIS & 005452 & \$DIVLI & 005434 & LI D\$5 & 005476 \\
\hline & & & \$[VD & 005476 & [IEXF & 006404 & [LLOE10 & 01370 \\
\hline & & & LLLIT; & $007=14$ & MUD\$FS & 010114 & MUID\$ME: & 010120 \\
\hline & & & MUDOIS & 010140 & \$MULD & 010152 & MLILI\$ $6 \Omega$ & 010164 \\
\hline & & & \$MLD & $0101 \leqslant 4$ & [SBRT & 011216 & $E \times P$ & 011422 \\
\hline & & & $A[I F \equiv$ IS & 011762 & \$ADDF & 011770 & A[IF $\$ S]$ & 012002 \\
\hline & & & \$A[IR & 012002 & $A D F \neq F$ & 012000 & ADF $\$ M S$ & 012012 \\
\hline & & & SUIF⿻ IS & 012026 & \$SLUEF & 012034 & SUIF\$S & 012046 \\
\hline . & & & \$SER & 012046 & SUIF\$F & 012052 & StIF \$HS & 012056 \\
\hline & & & DIIVF & 012116 & IIF $\$ S S$ & 012150 & कDUR: & 012130 \\
\hline & & & MIJF\$FS & 012134 & MUIF $\$ M S$ & 012140 & MUF IS: & 012152 \\
\hline & & & \$MUILF & 012160 & MUIF $\$ S S$ & 012172 & \$MLFi & 012172 \\
\hline & & & LI I \$F: & 012176 & DIIDMS & 012204 & 口IIDIS & 012210 \\
\hline & & & [II $\$ 5 S$ & 012212 & \$IVI & 012212 & MUI \&PS & 012234 \\
\hline & & & MUI \$MS & 012242 & MUI\$IS & 012246 & IAUI\$SS & 012250 \\
\hline & & & \$ML I & 012250 & कDTI & 012916 & $\$ \$ 1$ IT I & 012320 \\
\hline & & & \$\$SET & 014200 & SQRT & 014474 & $\$ \times \square I$ & 014624 \\
\hline & & & $X[I \$$ & 014636 & \$FWDI & 014636 & $\$ X F I$ & 015234 \\
\hline & & & $X F I \Phi$ & 015246 & \$FWR I & 015246 & AES & 015524 \\
\hline & & & AIF\$ & 015542 & IOR屯 & 01555 & AND韦 & 015562 \\
\hline & & & EDV\$ & 015570 & XIFF & 015572 & NHII\$1M & 015600 \\
\hline & & & NMI $\$ 1$ I & $015 \leqslant 20$ & ELEE\$ & 0150.30 & BEDF & 015632 \\
\hline & & & EGT $\neq$ & $015 \leqslant 40$ & BriE\$ & 015642 & BFifi & 015644 \\
\hline & & & BNE $\$$ & 015650 & ELT\$ & 015652 & CAI\$ & 015682 \\
\hline & & & CALD & 015670 & DFF\$F & 015720 & LMF\$P & 015724 \\
\hline
\end{tabular}




\begin{tabular}{|c|c|c|c|c|c|}
\hline $\begin{array}{l}\text { LMF\$ IS } \\
\text { SEMR }\end{array}$ & $\begin{array}{l}015740 \\
015760\end{array}$ & $\begin{array}{l}\text { \$CMFF } \\
\text { DNF \$P I }\end{array}$ & $\begin{array}{l}015746 \\
015772\end{array}$ & $\begin{array}{l}\text { CMF\$SS } \\
\text { CNF\$MI }\end{array}$ & \\
\hline CMF\$I I & $1600 \mathrm{~s}$ & $M F \$ I$ & 010012 & CMF 末PP & \\
\hline$M F \$ M F$ & $1 \leqslant 030$ & $M F \$$ IP & 016040 & $C M F \mp S P$ & 1604 \\
\hline$M F \$ F M$ & & $M F \$ M$ & 016060 & $C M F \$ I M$ & 6070 \\
\hline & & CUTBIE & & CUTBD & $<0$ \\
\hline$C L \$$ & & DL \$ & & EUTBF & \\
\hline FL: & & EI\$ & 172 & & \\
\hline \$EE: 1 & & $000 \%$ & 374 & I & 402 \\
\hline CFL\$SM & .00 & EPI\$SM & & CFF $\$ S M$ & 610 \\
\hline $\mathrm{P} \square \Phi S \mathrm{SM}$ & & DL\$S & & MOL\$OM & \\
\hline$D \$ O F$ & & $D \$ O A$ & & MOD\$ IP & \\
\hline II IM & & $D+1 A$ & & DLI\$SA & \\
\hline & & & & \$MS & \\
\hline & & $\mathrm{PP}$ & & D\$MF & \\
\hline & & $\$ M \mid A$ & & $\Phi F A$ & \\
\hline & & & & $\sin$ & \\
\hline & & & & & \\
\hline D\$\$F & & NE\$ & & & \\
\hline & & & & HKEF & \\
\hline DEXI & & & & & \\
\hline & & $=\$ 3$ & & & \\
\hline$\$$ & & & & & \\
\hline$\$ S M$ & & & & & \\
\hline \$IF & & & & & \\
\hline$F \$ O P$ & & $D F \$ M M$ & & $=$ DrA & \\
\hline IF $\$ M F$ & 01 & $D F \$ F M$ & $6 \leqslant 6$ & MOF \$FA & \\
\hline IF \$FP & 01 & JF\$RS & 102 & MOF \$FM & \\
\hline IF \$FiA & 20 & IF $\$ F F$ & 24 & \$SIMRT & \\
\hline$k$ & 02 & $\Gamma \times B$ & & TF:S & \\
\hline & & RTB & & HDTT & \\
\hline & & & & $=10$ & \\
\hline & & & & $\Phi M$ & \\
\hline & & & & & \\
\hline & & & & & \\
\hline & & & & II: & \\
\hline$\$$ IA & & & & $I \$ M S$ & \\
\hline DMA & & MII & & $\$ 38$ & \\
\hline$B I$ & & $\mathrm{SM}$ & & \$S & \\
\hline & & & & & \\
\hline & & & & & \\
\hline & & & & & \\
\hline & & & & & \\
\hline & & & & $I S$ & \\
\hline & & & & IM & \\
\hline DIA & 02 & $\$ 115$ & & $I \$ M M$ & \\
\hline$\$ M A$ & & $\$ 05$ & & boM & \\
\hline$I \$ D A$ & 572 & $\$ 15$ & & $I \neq 1 \mathrm{M}$ & \\
\hline$\$ 1 \mathrm{~A}$ & & & & [ & \\
\hline & & & & & \\
\hline & & & & & \\
\hline & & & & & \\
\hline & & & & & \\
\hline$\Phi P F$ & & \$MF & & \$PS & \\
\hline$\$ F M$ & & & & & \\
\hline & & & & $\$ P F$ & \\
\hline I $\$ P S:$ & & & & $1 I \$ F \cdot M$ & \\
\hline & & & & DI\$FF & \\
\hline & & & & I SF'M & \\
\hline & & & & DIF & \\
\hline
\end{tabular}




\begin{tabular}{|c|c|c|c|c|c|c|c|c|}
\hline & & & SIII DIF & 025072 & :U1 I \$:SP & 025074 & $\because 1 I \$ F P$ & 025102 \\
\hline & & & $\begin{array}{l}\text { SUI IMP } \\
\text { SUI\$PA }\end{array}$ & $\begin{array}{l}025106 \\
025132\end{array}$ & $\begin{array}{l}\text { SuI \$PS } \\
\text { ISN\$ }\end{array}$ & $\begin{array}{l}025114 \\
025140\end{array}$ & $\begin{array}{l}\text { SUI IPM } \\
\text { \$ INTR }\end{array}$ & $\begin{array}{l}025124 \\
025144\end{array}$ \\
\hline & & & LSN" & 025160 & \$LSNTR & 025167 & SUI \$SO & 025320 \\
\hline & & & SUI\$SA & 025324 & SIII\$SM & 025330 & SII\$IS & 02533 \\
\hline & & & SI_II\$IA & 025340 & SIJI\$ IM & 025344 & SUI \$MS & 02535 \\
\hline & & & $D ! I I \$ M A$ & 025354 & SUI \$MM & 025360 & CHLDMI & 02536 \\
\hline & & & CML\$SI & $025361 \mathrm{~s}$ & MILL:SM & 025374 & MUL $\$ A A$ & 02540 \\
\hline & & & MOL\$MS & 025404 & MULL\$MM & 025414 & MOLL \$MA & 02542 \\
\hline & & & MDL & 025424 & MOL\$PF & 025432 & MOL TIP & 02543 \\
\hline & & & MUL \$PM & 025446 & MOL\$PS & 025454 & $M O L \$ P A$ & 02546 \\
\hline & & & MOL $\triangle M$ & 025466 & MDL\$IA & 025474 & MDL\$IF & 02550 \\
\hline & & & LLE\$ & 025512 & LED\$ & 025514 & LET\$ & $\lcm{2552}$ \\
\hline & & & LBES & 025524 & LNE\$ & 025534 & LLTक & 025 \\
\hline & & & DML.\$FS & 025542 & CML $\$ P I$ & 025550 & CML\$PM & 0255 \\
\hline & & & TSL末'S & $0255 i 616$ & TBL\$M & 025572 & TSL\$I & 02557 \\
\hline & & & TGL\$F & 025604 & MOD & $025 \leqslant 12$ & NMI \$IM & 0.565 \\
\hline & & & NMI DMM & 025706 & MMI\$PM & 025714 & NFI $\$ I M$ & 02532 \\
\hline & & & NF' I $\$ M M$ & 025730 & NF I \&FM & 025734 & NMI $\$ 1 F$ & 02574 \\
\hline & & & \$FDF'4 & $0280 \geq 0$ & DPEPRS & 026020 & \$FOPRO & 02603 \\
\hline & & & FET $\$ \Pi$ & 028040 & RET $\$ L$ & 026106 & RET $\$ F$ & 02611 \\
\hline & & & FET\$I & 028120 & FET\$ & 026122 & SAVFIOD & 02615 \\
\hline & & & THRD\$ & 026334 & \$STPS & 026336 & STP\$ & 02634 \\
\hline & & & \$STP & 026344 & FDM\$ & 026350 & \$EXI T & 02637 \\
\hline & & & \$1TT IS & 028514 & \$\$ITIS & 028516 & TSI \$5 & 0204 \\
\hline & & & TS[1\$S & 026642 & TSF\$S & 026645 & TSD\$M & $02 \leqslant 6$ \\
\hline & & & 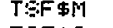 & 026462 & TSI\$M & 026652 & TSD\$I & 02665 \\
\hline & & & TSF\$I & 026656 & TSI\$I & 024656 & TSDsF & 02666 \\
\hline & & & $T S F \$ P$ & 926602 & $T \subseteq I \$ P$ & 026662 & TVL: & 02667 \\
\hline & & & $\begin{array}{l}\text { \$TVL } \\
\text { TULI\$ }\end{array}$ & $\begin{array}{l}026670 \\
026704\end{array}$ & $\begin{array}{l}\text { TVF\$ } \\
\text { \$TVD }\end{array}$ & 026704 & $\begin{array}{l}\text { SUT } \\
\text { TVWDE }\end{array}$ & \\
\hline & & & \$TVQ & 026712 & TUP\$ & 025720 & \$TVP & $02 \leq 72$ \\
\hline & & & TVI\$ & 026726 & \$TVI & 026726 & \$VR INT & 02706 \\
\hline & & & $\Xi A D \$ F M$ & 027064 & SVII\$PM & 027104 & SAD\$PF & 02712 \\
\hline & & & SUD\$PP & 027144 & SAL\$IM & 927164 & SAD\$SM & 02716 \\
\hline & & & SUDSIM & 027202 & SVD\$SM & 027204 & SAD\$MM & 02722 \\
\hline & & & SUD\$MM & 027226 & $S A \square \$ I P$ & 027232 & SAD\$:PP & 0272 \\
\hline & & & SVDs IP & 027250 & SVII\$SF & 027252 & SAII\$MP & 02727 \\
\hline & & & SUDJMF & 027274 & SAF \$F' & 1027300 & SUFAFM & 02731 \\
\hline & & & SAF \$PF & 027340 & SUF $\$ F$ & 027356 & SAF $\$$ IM & 0273 \\
\hline & & & SAF\$SM & 027374 & SUF\$IM & 027406 & SUF\$SM & 02741 \\
\hline & & & SAF \$MM & 027430 & SUF\$MM & 027434 & $\Xi A F \$$ IF & 02744 \\
\hline & & & SAF\$SF & 027442 & SVF\$IF & 027454 & SUFक्\$P & 02745 \\
\hline & & & SAF कMF & 027476 & SVF SMF & 027502 & SAI\$IM & 027 \\
\hline & & & $\begin{array}{l}\text { SAI\$SM } \\
\text { SUI\$SM }\end{array}$ & $\begin{array}{l}027510 \\
027542\end{array}$ & $\begin{array}{l}\text { \$EUIND } \\
\text { SAI \$MII }\end{array}$ & $\begin{array}{l}027514 \\
027552\end{array}$ & SUI IIM & 0275 \\
\hline & & & SAL\$IM & 027562 & SAL\$SM & 027564 & SUL\$IM & 0275 \\
\hline & & & SUL\$SM & 027574 & SAL\$MH & 027602 & SULTIMM & $027<0$ \\
\hline & & & SAL\$IP & 027612 & SAL\$SP & $027 \$ 14$ & SVL\$IF & $\begin{array}{l}02760 \\
02762\end{array}$ \\
\hline & & & SVL+SF & $027 \leqslant 24$ & SAL\$MF & 027632 & SUL DMP & 02763 \\
\hline & & 100 & $(R W, D$, & IBL, REL, & OURI & & & \\
\hline & 027712 & 000362 & ( RW, I, & _C:L, REL, & (ㅁN) & & & \\
\hline & & & INEIEX & 027712 & INSEF'T & 030024 & IFEEK & 03012 \\
\hline & & & IPDKE & 0.30132 & SCIPPY & 030142 & STRFAD & 03022 \\
\hline IIt & 030274 & 00026 & (FW, I, & - $\mathrm{L}, \mathrm{REL}$, & CON) & & & \\
\hline & & & SIFEALI & 0.30274 & & & & \\
\hline & & & SRW I, & - CL, REL, & SON & & & \\
\hline & & & \$\$OTS1: & 030554 & MATINV & 054224 & GF I T2 & 05437 \\
\hline & & & EKGBD & 060232 & FIJF I T & 060672 & CTAIL & 06261 \\
\hline
\end{tabular}




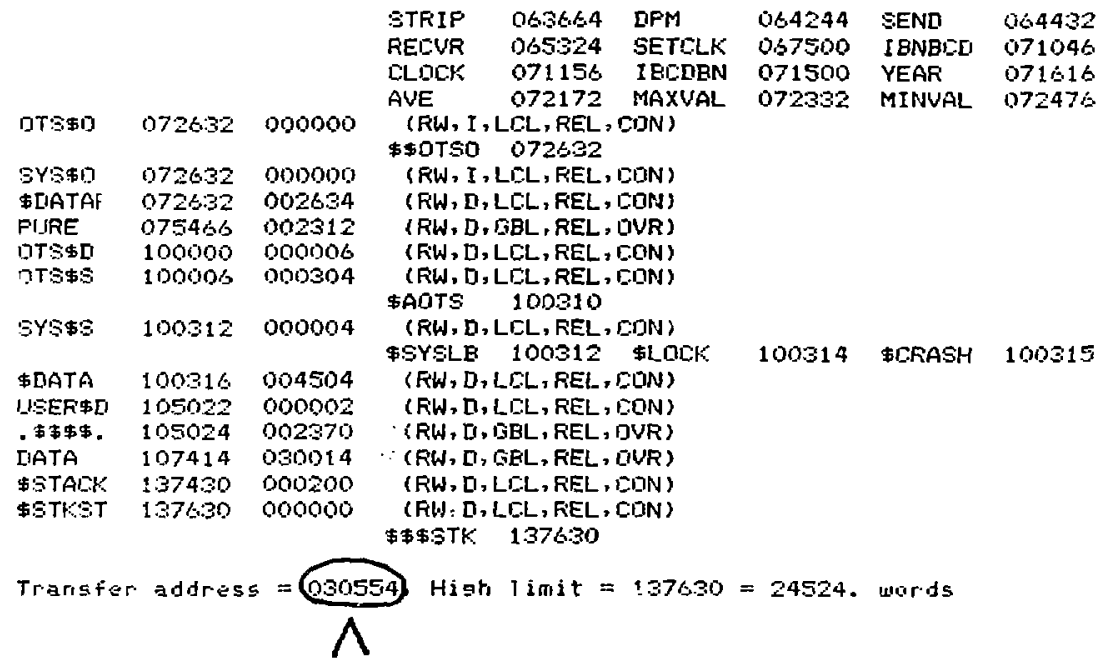

\section{This address must be loaded into location $4 \phi_{B}$ of PROM.}

